\title{
Wind Pressures on 4:12-sloped Hip Roofs of L- and T-shaped Low-rise Buildings
}

\author{
Shuai Shao ${ }^{1}$, Ted Stathopoulos, F.ASCE², Qingshan Yang ${ }^{3}$, Yuji Tian ${ }^{4}$
}

${ }^{1}$ Ph.D. Student, Beijing's Key Laboratory of Structural Wind Engineering and Urban Wind Environment, School of Civil Engineering, Beijing Jiaotong University, Beijing, China 100044 (corresponding author). E-mail: shuaishao.concordia@hotmail.com

2 Professor, Centre for Zero Energy Building Studies, Department of Building, Civil, and Environmental Engineering, Concordia University, Montreal, Quebec, Canada H3G 1M8. E-mail: statho@bcee.concordia.ca

${ }^{3}$ Professor, Beijing's Key Laboratory of Structural Wind Engineering and Urban Wind Environment, Beijing, China 100044; School of Civil Engineering, Chongqing University, Chongqing, China 400044. E-mail: qshyang@cqu.edu.cn

${ }^{4}$ Professor, Beijing's Key Laboratory of Structural Wind Engineering and Urban Wind Environment, School of Civil Engineering, Beijing Jiaotong University, Beijing, China 100044. E-mail: yujitian@bjtu.edu.cn

Abstract: A comprehensive wind tunnel experimental study for 4:12-sloped hip roofs of L- and T-shaped low buildings was carried out in a simulated open terrain exposure to examine wind load characteristics and assess the applicability of wind provisions specified by ASCE-7 for such geometries. Results show that considering roof shape effects, hip roofs with rectangular or complex plans perform differently from rectangular gable roofs and incur smaller local and area-averaged suction. For L- and T-shaped hip roofs, distinctive pressure distributions occur, particularly along roof eaves near building re-entrant corners, where considerable suction appears for the wind blowing towards these building re-entrant corners. Furthermore, the building length-to-width aspect ratio effects are in most cases moderate. Generally, ASCE-7 wind provisions are adequate for L- and T-shaped hip roofs, except for the edge zone along ridge and hip with large areas, for which measured values exceed the code-specified wind pressure coefficients. Finally, it was found more appropriate to utilize the entire Lor $\mathrm{T}$ - shaped roof dimensions, as opposed to the rectangular section only, to determine the least horizontal dimension of such non-rectangular hip roofs for the definition of roof zones.

Keywords: Low-rise buildings; L- and T-shaped roofs; Local and area-averaged wind loads; Aerodynamics; Wind tunnel tests; Wind standards and codes 


\section{Introduction}

Low-rise buildings constructed for residential, industrial and other purposes form the majority of structures around the world. However, wind-induced damage to roof corners and edges has frequently happened (Lin and Surry 1998; Uematsu and Isyumov 1999; Gavanski et al. 2013), especially during extreme wind hurricane events (Van de Lindt et al. 2007). To improve the structural safety, extensive wind tunnel studies have been conducted (as comprehensively summarized in Stathopoulos 1984a; Uematsu and Isyumov 1999, etc.). In fact, roof shapes have been considered as a critical factor in wind-induced pressures (Stathopoulos 2003), as they alter the wind separation significantly. Among the wind tunnel studies examining roof shapes, most focused on those with flat or gable roofs (e.g., Holmes 1983; Kanda and Maruta 1993; Holmes 1994; Lin et al. 1995; Case and Isyumov 1998; Stathopoulos and Wang 2001; Alrawashdeh and Stathopoulos 2015). A limited number of studies examined the aerodynamic performance of rectangular hip roofs (Meecham et al. 1991; Xu and Reardon 1998; Ahmad and Kumar 2002 and Gavanski et al. 2013). Although other roof configurations have also been studied, such as stepped roofs (e.g., Stathopoulos and Luchian 1990), mono-slope roofs (e.g., Stathopoulos and Mohammadian 1986) and multi-span roofs (e.g., Stathopoulos and Saathoff 1991), the majority of the tested models were based on rectangular building plans.

With very few exceptions, research has not paid attention to roof pressures of L- or T-shaped low buildings (Stathopoulos and Zhou 1993; Kikuchi et al. 2001; Tao et al. 2011; Nie et al. 2016). A numerical pressure prediction model for a symmetrical L-shaped building with a flat roof was presented by Stathopoulos and Zhou (1993). Results under the normal wind direction were found similar for L-shaped and rectangular buildings, while differences were observed for oblique wind cases. 
Recommendations for L-shaped flat-roofed low- and mid-rise models. It was recognized that interaction of conical vortices shed from windward corners and the upwind wing influences local pressure distributions on L-shaped models. Moreover, the AIJ (1993) Recommendations seem to underestimate the actual values and areas of local pressures. Recently, two types of L-shaped low building models were examined in wind tunnel studies by Tao et al. (2011). These contained (1) two gable-roofed building wings with roof slope angles from $21.8^{\circ}$ to $47^{\circ}$; (2) one building wing consisted of a $30^{\circ}$-sloped hip roof and the other wing with a $41^{\circ}$-sloped gable roof. The study found that the critical suction intensifies with the decrease in roof slope. Additionally, Nie et al. (2016) investigated only mean wind pressure distributions for eleven gable-roofed T-shaped models with roof angles ranging from $15^{\circ}$ to $60^{\circ}$ and one $30^{\circ}$-sloped hip-roofed configuration through numerical and wind tunnel test methods. Results showed that roof pitches and wind directions influence the roof wind pressures considerably. Generally, all these related studies mainly concentrated on non-rectangular flat, gable or steep hip roofs (roof inclination angle larger than $30^{\circ}$ ). Therefore, it is still questionable how L- or T-shaped buildings with 4:12 $\left(18.4^{\circ}\right)$ sloped hip roofs, and other complex-roofed buildings perform when subjected to high wind.

The lack of comprehensive research for L- and T-shaped buildings also influences the field of practical design. Wind provisions of codes and standards (e.g., CEN 2004; ASCE-7 2010; NBCC 2015) focus on rectangular buildings and do not include provisions for L- or T-shaped structures. Whether these provisions are applicable to complex L- and T-shaped cases remains an open question. Hence, an effective comparison between the measured data of such complex buildings and the related pressure coefficients provided by the wind standards and codes of practice is necessary. 
rectangular, L- and T-shaped low building models with 4:12 sloped gable (only for the rectangular case) or hip roofs, regarding different wind directions, roof shapes and length-to-width aspect ratios. The purposes of this study are to provide the necessary information about the characteristics of roof wind pressures of L- and T-shaped hip-roofed low-rise buildings; and to examine the applicability of wind provisions specified by the American standard (ASCE-7 2010) for roof components and cladding of non-rectangular buildings.

\section{Experimental Setup}

\section{Building models}

Twenty gable- or hip-roofed low-rise building models with rectangular, L- and T-shaped plan views were constructed at a scale of 1:200. This length scale was examined to be permissible for both local and area loads (Stathopoulos and Surry 1983). All models (one rectangular gable-roofed, four rectangular and fifteen complex hip-roofed cases) have a 4:12 pitch roof angle, a full-scale equivalent mean roof height of $5.8 \mathrm{~m}$ and horizontal dimensions ranging from $10 \mathrm{~m}$ to $40 \mathrm{~m}$. Figure 1 presents the plan views, model dimensions, pressure tap layouts and the definition of wind directions for all model configurations. Five L-shaped models with various horizontal aspect ratios $L: W$, namely 7:7, 9:7, 11:7, 9:9 and 11:9 were tested. Ten T-shaped buildings, with dimensions $L$ and $L$ ' ranging from $22.5 \mathrm{~m}$ to $40.0 \mathrm{~m}$, and width $W$ varying between $17.5 \mathrm{~m}$ and $32.5 \mathrm{~m}$ in full scale were examined.

Considering the symmetry of the model, the investigated wind directions ranged from $0^{\circ}$ to $180^{\circ}$ or $0^{\circ}$ to $350^{\circ}$, with $5^{\circ}$ or $10^{\circ}$ intervals, as shown in Fig. 1 . Wind tunnel test data were collected from two types of basic tested models with 32 and 52 pressure taps on the gable and hip roofs, respectively, as indicated in Fig. 2 (a). The basic models with as many pressure taps as possible are combined with component models of similar geometries (as seen in Fig. 2 (b)) to form the complete rectangular, L- or 
T-shaped models and scan critical pressure on roof end components as shown in Fig. 2 (c). Pressure taps have been deliberately concentrated on roof edges, ridges and corners, where the most critical suction is anticipated. Note that more than 40 modular tests were carried out to cover more critical and distinctive roof regions and wind cases, except those on interior cross roof sections, considering the less probable occurrence of critical suction along valleys and other areas on these roof blocks for current building configurations (Tao et al. 2011; Nie et al. 2016).

\section{Boundary layer wind tunnel simulation}

The experiments were conducted in the boundary layer wind tunnel of the Building Aerodynamics Laboratory, Concordia University. This low-speed straight-flow wind tunnel has a working section of $1.8 \mathrm{~m}$ in width, $12.2 \mathrm{~m}$ in length and a variable height ranging from $1.4 \mathrm{~m}$ to $1.8 \mathrm{~m}$, as seen in Fig. 3 with an installed tested building model. More detailed information about the wind tunnel construction and simulation can be found in Stathopoulos (1984b). In this study, the open country exposure (roughness length $z_{o}=0.01 \mathrm{~m}$ ) was used, since a building is generally immersed in larger wind velocities and consequently experiences more critical wind pressures in this exposure condition (Stathopoulos 1984a; Case and Isyumov 1998; Gavanski et al. 2013). Accordingly, the wind speed characteristics are assumed to follow the power-law model with an exponent $\alpha$ of 0.15 . The wind velocity at the gradient height $\left(\mathrm{Z}_{\mathrm{G}}=60 \mathrm{~cm}\right)$ was $11.0 \mathrm{~m} / \mathrm{s}\left(\overline{\mathrm{V}}_{\mathrm{G}}\right)$. Figure 4 depicts the profiles of mean wind velocity, referenced at the gradient height $\left(\bar{V}_{\mathrm{Z}} / \overline{\mathrm{V}}_{\mathrm{G}}\right)$ and turbulence intensity $\left(\mathrm{I}_{\mathrm{U}}\right)$ at the experimental section. Measurements were carried out by using the 4-hole Cobra probe (TFI).

\section{Pressure measurements and pressure coefficients}



measured by connecting these brass tubes with the ZOC33/64Px through the $550 \mathrm{~mm}$ length flexible plastic tubes with exterior and interior diameters of $2.18 \mathrm{~mm}$ and $1.37 \mathrm{~mm}$. The traditional brass restrictors were used within the plastic tubes at the distance of $300 \mathrm{~mm}$ away from the pressure taps to correct the measured data for the frequency response effect of the tubing system (e.g., Stathopoulos and Saathoff 1991). The sampling rate and duration of each record are $300 \mathrm{~Hz}$ (300 samples per second) and 27 seconds on a wind-tunnel scale corresponding to approximately 0.5 hours in full scale, assuming a velocity scale in the wind tunnel of about $1: 3$. scale) and expressed as, 2013; Ding and Chen 2015; Yang and Tian 2015). In this study, negative peak pressure coefficients 
Specifically, a standardized non-Gaussian process $x$ can be related to an underlying standardized Gaussian process $u$ (Grigoriu 1984) as,

$$
x=g(u) \text { or } u=g^{-1}(x)
$$

where $g()$ is a translation function and $g^{-1}()$ is the inverse function of $g()$. Consequently, the non-Gaussian peak value estimation can be translated into corresponding Gaussian peak value estimation through a monotonic and increasing function $g()$. Moreover, these translation processes can be determined by Eqs. (3) and (4) for non-Gaussian processes of softening ( $x_{\text {softening }}$, kurtosis larger than 3) and hardening ( $x_{\text {hardening }}$, kurtosis smaller than 3), respectively (Winterstein 1988; Ding and Chen 2015).

$$
\begin{gathered}
x_{\text {softening }}=g(u) \approx k\left[u+h_{3}\left(u^{2}-1\right)+h_{4}\left(u^{3}-3 u\right)\right] \\
u=g^{-1}\left(x_{\text {hardening }}\right) \approx b_{2} x_{\text {hardening }}+b_{3}\left(x_{\text {hardening }}^{2}-m_{3} x_{\text {hardening }}+1\right)+b_{4}\left(x_{\text {hardening }}^{3}-m_{4} x_{\text {hardening }}-m_{3}\right)
\end{gathered}
$$

where $m_{3}$ and $m_{4}$ are skewness and kurtosis coefficients of $x$, respectively; $h_{3}, h_{4}, k$ and $b_{2}$, $b_{3}, b_{4}$ are the model coefficients for softening and hardening processes, respectively. These model coefficients can be calculated by solving nonlinear equations for target unit variance, skewness $m_{3}$ and kurtosis $m_{4}$ of $x$ (Winterstein and Kashef 2000). In this study, these model coefficients were obtained based on numerical solutions addressed in Yang et al. (2013) and Ding and Chen (2015). The peak estimation has been examined to be efficient and accurate consistently for both mildly and strongly non-Gaussian wind pressures on complex roofs of low buildings, as also presented in Peng et al. (2014). Note that, the skewness mapping method (Peng et al. 2014), which was also verified in Liu et al. (2017), was applied to those cases beyond the monotonic application region of the moment-based translation model. 
peak pressure coefficients $\hat{C}_{p}$ have been converted into the equivalent coefficients of $\left(G C_{p}\right)_{\mathrm{eq}}$ through a normalized process, following the methodology of St. Pierre et al. (2005) and Gavanski and Uematsu (2014). The conversion is shown as follows,

$$
\left(G C_{p}\right)_{\text {eq }}=\frac{\frac{1}{2} \rho V_{\text {ref }, z_{0}=0.01 \mathrm{~m}, 0.5 \mathrm{~h}}^{2} \hat{C}_{p}}{\frac{1}{2} \rho V_{10 \mathrm{~m}, z_{0}=0.03 \mathrm{~m}, 3 \mathrm{sec}}^{2} K_{\mathrm{zt}} K_{\mathrm{z}} K_{\mathrm{d}} I}=F_{\mathrm{eq}} \times \hat{C}_{p}
$$

where $F_{e q}$ in Eq. (5) can be broken down into,

$$
F_{\text {eq }}=\left(\frac{V_{\text {ref, } z_{0}=0.01 \mathrm{~m}, 0.5 \mathrm{~h}}}{V_{10 \mathrm{~m}, z_{0}=0.01 \mathrm{~m}, 0.5 \mathrm{~h}}}\right)^{2}\left(\frac{V_{10 \mathrm{~m}, z_{0}=0.01 \mathrm{~m}, 0.5 \mathrm{~h}}}{V_{10 \mathrm{~m}, z_{0}=0.03 \mathrm{~m}, 0.5 \mathrm{~h}}}\right)^{2}\left(\frac{V_{10 \mathrm{~m}, z_{0}=0.03 \mathrm{~m}, 0.5 \mathrm{~h}}}{V_{10 \mathrm{~m}, z_{0}=0.03 \mathrm{~m}, 3 \mathrm{sec}}}\right)^{2} \times \frac{1}{K_{\mathrm{zt}} K_{\mathrm{z}} K_{\mathrm{d}} I}
$$

and $K_{\mathrm{zt}}, K_{\mathrm{z}}, K_{\mathrm{d}}$ and $I$ denote in ASCE-7 (2010) the topographic factor, velocity pressure exposure factor evaluated at mean roof height, wind directionality factor and importance factor, respectively. The directionality factor $K_{\mathrm{d}}$ was assumed to be 1.0 , as the reduction of the directionality effects on peak wind pressures was not considered in the current study. The assumption of $K_{\mathrm{zt}}=I=1.0$ was made to reflect common situations. The factor $K_{\mathrm{z}}$ was calculated to be 0.89 , based on the $5.8 \mathrm{~m}$ reference height and open terrain in ASCE-7 (2010). It should be noted that the first velocity ratio in Eq. (6) was taken from the measured wind speed profile in the present tests. The second velocity ratio term was calculated approximately using mean-hourly wind speed model of Engineering Science Data Unit (ESDU 1982) based on the derivations of (Deaves 1981; Irwin 2006). Finally, the third ratio has been obtained from the Durst curve as shown in ASCE-7 (2010) (FIGURE C26.5-1). The factor $F_{\text {eq }}$ in Eq. (5) was determined as 0.43 for the present study.

\section{Validation of measured data}

In this section, some partial validation of measured data has been discussed through the comparisons with previous research results (Holmes 1983; Meecham et al. 1991; Xu and Reardon 1998 and Gavanski et al. 2013) as summarized in Table 1. Figure 5 shows mean pressure coefficients on the 
gable-roofed model with a roof angle of $15^{\circ}$ (Holmes 1983) and similar coefficients from the present study for a model with the roof angle of $18.4^{\circ}$ (4:12 slope), for two wind directions, $0^{\circ}$ and $90^{\circ}$. Despite the differences of the model configurations and the upstream terrain conditions, a good general agreement on the trend and magnitude of mean pressure results is shown. For hip-roofed buildings, Fig. 6 depicts a comparison of mean pressure distributions for hip roofs for $0^{\circ}, 45^{\circ}$ and $90^{\circ}$ wind directions presented by Meecham et al. (1991), Gavanski et al. (2013) and the present study with the same roof slopes and simulated roughness length $\left(z_{o}\right)$. For each wind direction, good similarities can be found for critical pressure areas and values. However, some differences are also found for the leading windward edges compared with Meecham et al. (1991) for $90^{\circ}$ wind and around the windward/leeward eave edges compared with Gavanski et al. (2013) under $45^{\circ}$ wind. These are mainly attributed to the different building dimensions and pressure tap densities, which affect the pressure magnitudes and the result contours.

Furthermore, the most critical pressure coefficients regardless of wind direction are shown in Fig. 7 (a) - (b), compared with Holmes (1983) for the gable roof, and Xu and Reardon (1998) for the hip roof, respectively. Generally, the peak pressure coefficients match well for both gable and hip roofs, although somewhat higher peak suction is shown in Holmes (1983), and Xu and Reardon (1998) for some areas, such as eave corners. This may be attributed to the influence of different geometries, pressure tap arrangements and especially, the rougher exposure terrains used in the previous studies, which induce more intensive peak pressure coefficients (Stathopoulos and Wang 2001), due to the smaller reference velocity pressure $\left(0.5 \rho \overline{\mathrm{V}}_{\text {ref }}^{2}\right)$ as expressed in Eq. (1).

In general, the aforementioned comparative process responds well to the reliability and validity of the present test data and peak value estimation for rectangular roof configurations. 


\section{Basic Aerodynamics and Wind Load Distributions}

\section{Rectangular buildings with gable or hip roofs}

Figure 8 presents the roof pressure distributions of the rectangular gable-roofed building ( $L: W=4: 2)$ and two hip-roofed buildings ( $L: W=3: 2$ and 5:2), for typical wind directions $\theta$ of $0^{\circ}, 45^{\circ}, 90^{\circ}$. Note that, by using symmetry, the mean and peak pressure coefficients are presented on the upper and lower parts of each diagram, respectively for each wind direction. Similar trends between mean and peak pressure results for each model are found for all wind directions, similar to the findings of Ahmad and Kumar (2002), and Gavanski et al. (2013).

For the gable roof presented in Fig. 8, large mean or peak suction appears around the windward leading edges when wind directions are perpendicular or parallel to the ridge $\left(\theta=0^{\circ}\right.$ or $\left.90^{\circ}\right)$, as do leeward areas of the ridge with the oblique approach wind $\left(\theta=45^{\circ}\right)$. Previous research (e.g., Kanda and Maruta 1993; Stathopoulos and Wang 2001; Gavanski et al. 2013) focused on roof slope angle effects on vortex generations around the gable-roofed buildings, which influence the wind-induced pressures. In this study, the intermediate roof slope $\left(4: 12,18.4^{\circ}\right)$ frequently leads to two successive wind separations at the leading windward edge and ridge, as clearly indicated in Fig. $8\left(\theta=0^{\circ}\right)$. In addition, for the oblique approach wind $\left(\theta=45^{\circ}\right)$, critical mean and suction with larger pressure gradients occur at the leeward part of the ridge, compared to the results near the windward edge, for the $90^{\circ}$ wind. These are mainly attributed to the interaction of vortices (from leading edge separation) and bubbles (from secondary separation at the ridge).

Regarding the hip roofs in Fig. 8, when the wind is perpendicular to one of the walls ( $\theta=0^{\circ}$ and $90^{\circ}$ ), intense suction is observed along the eaves or hip end edges. Moderate secondary flow separations at the ridge and hip lines are indicated, similar to those of the gable roof. For the oblique 
wind direction $\left(\theta=45^{\circ}\right)$, the corner vortices, which appear on gable-roofed edges, are not clear here, mainly due to the sloped hipped-end surfaces. However, significant negative wind pressures (suction) occur at the leeward parts of the ridge and hip lines. In essence, the hip lines act to some extent like another ridge lines (Xu and Reardon 1998; Gavanski et al. 2013). In absolute terms, the most critical suction at the leeward ridge and hip lines decreases nearly $40 \%$, in comparison to the gable roof suction at similar locations. Clearly, as previously found, the hip roof performs better aerodynamically for the wind-resistance of roofs (Meecham et al. 1991; Xu and Reardon 1998; Gavanski et al. 2013). Also, the length-to-width aspect ratio effects on wind load distributions are minimal, as mentioned by Stathopoulos (1984a). Quite similar trends and magnitudes are found not only for the two geometries of hip roofs shown in Fig. 8, but also for other hip-roofed cases ( $L / W$, ranging from 1.5 to 3.0), which are not presented in this paper.

\section{Complex L-shaped buildings}

Two sets of L-shaped buildings ( $L: W=7: 7$ and $L: W=11: 7)$ are selected as typical examples to present the basic aerodynamics and wind load distributions, based on the investigations into all five tested buildings - see Fig. 1. Mean and peak pressure coefficients referenced to the "mean roof height" are presented in Figs. 9 and 10, respectively, for wind directions, $\theta$ of $0^{\circ}, 45^{\circ}, 90^{\circ}, 135^{\circ}, 180^{\circ}, 225^{\circ}$, $270^{\circ}$ and $315^{\circ}$.

Generally, similar to the rectangular cases, relatively intensive suction is observed around the leading windward edges and leeward ridge/hip lines. The length-to-width ratio, $L / W$ (ranging from 1.0 to 1.6) has a slight effect on the mean and peak wind pressures for L-shaped roofs. Also, mean and peak pressures for each L-shaped roof keep similar patterns. Therefore, the following discussion mainly refers to the peak wind pressures (suction). 

be examined into two groups, according to the relative locations of building re-entrant corners (roof valleys):

(1) For $\theta=180^{\circ}$ or $270^{\circ}, 135^{\circ}$ or $315^{\circ}$ and $225^{\circ}$, the re-entrant corners of L-shape buildings are on the leeward sides. Under these wind cases, minimal differences in pressure coefficients of upwind roof blocks are found between L-shaped and rectangular buildings with hip roofs. In absolute terms, large peak pressure coefficients ranging from -2.4 to -2.8 appear along the lee of hip and ridge lines for oblique wind directions $\left(135^{\circ}, 315^{\circ}\right.$ and $\left.225^{\circ}\right)$. Furthermore, in the cases of wind azimuths normal to walls $\left(\theta=180^{\circ}\right.$ and $\left.270^{\circ}\right)$, more critical suction (with pressure coefficients of -3.0 , approximately) is found on windward roof edges; whereas for the downwind roof blocks, the suction and pressure 
valley. In addition, particularly intensive negative pressure coefficients of approximately -2.0 are observed along the roof eave parallel to wind near the roof valley. However, peak pressure coefficients around -3.0 on the windward roof eave vertical to the wind show a better agreement with those of the rectangular cases and are hardly influenced by the upwind blocks. Generally, the most particular wind direction is $45^{\circ}$, for which large negative mean and peak pressure coefficients of -1.5 and -3.5 occur on both roof eaves near the valleys due to the increased wind separation induced by the two vertical building blocks. With the increase in the building block length, the critical values near the roof re-entrant corner keep relatively stable but suction reduces gradually away from the valley.

\section{Complex T-shaped buildings}

Based on the consideration of results from all 10 T-shaped models - see Fig. 1 - under each wind direction, three sets of mean and peak pressure coefficients for T-shaped models with aspect ratios of $L: L^{\prime}: W=7: 3: 7,7: 3: 9$ and 9:3:9 under representative wind directions of $0^{\circ}, 45^{\circ}, 135^{\circ}$ are chosen and presented in Figs. 11 and 12, respectively. These three building models and wind directions can represent the cases of critical pressure features and wind conditions. In addition to making T-shaped building comparisons, the results of one basic L-shaped model $(L: W=7: 7)$ are also included in the comparisons.

In general, T-shaped buildings act to some extent like those of L-shaped plans in most cases, with similar wind conditions, since current T-shaped models can be considered as a combination of L-shaped models. Concretely, regarding the $0^{\circ}$ wind direction, the upwind hip-end roof block and the other right (or left) downwind block consist of an L-shaped model, and very similar findings are presented, here. For instance, respective peak suction reduction and increase along windward hip-end edges and right (or left) roof eaves occur on this upwind roof block of the T-shaped model, as well as 
those L-shaped cases. Moreover, the previously mentioned suction reduction at the lee of hip line on the side of the valley of the L-shaped roof is also observed along the left and right hip lines on this upwind roof block of the T-shaped case. Regarding the wind directions of $45^{\circ}$ and $135^{\circ}$, the surface pressure features of T-shaped roofs can be divided into the combinations of an L-shaped roof component at the right side and a rectangular hip-end component at the left side. The pressure distributions of this right hypothetical L-shaped roof component (e.g., $\theta=45^{\circ}$ ) shown in Figs. 11 and 12 , match those of the actual L-shaped building with $\theta=45^{\circ}$, as shown in Figs. 9 and 10, respectively. Moreover, the left hypothetical rectangular hip-end component (e.g., $\theta=45^{\circ}$ ) can also be considered as the corresponding left building component of an actual L-shaped building under $135^{\circ}$ wind direction. These findings are also appropriate for T-shaped models, under different wind directions (e.g., 135 $)$. Also, the horizontal aspect ratios influence the roof wind pressures of the T-shaped cases moderately for the investigated ratio range from $1.3\left(\left(L+L^{\prime}\right) / W\right)$ to $2.3\left(\left(L+L^{\prime}\right) / W\right)$.

\section{Most critical negative pressure distributions}

After discussing the basic aerodynamics and local wind pressure distributions under different wind directions, the most critical pressure coefficients for all rectangular and complex models regardless of wind directions are presented in Fig. 13. Generally, the extreme suction appears along roof edges, hip and ridge lines on all types of roofs. Considering roof shape (gable and hip roofs) effects, larger critical suction as large as -4.6 appears along ridge lines and roof corners on the gable roof, compared with those critical pressure coefficients about -3.5 around the hip and ridge lines on rectangular hip roofs. For the building plan effect, it is clear that distinctively considerable suction occurs along both roof eaves on the sides of building re-entrant corners, comparing the results between rectangular and complex hip roofs. However, the influence of building plan is minimal for L- and T-shaped models. In 
addition, the horizontal aspect ratio impact is investigated to be moderate, again.

\section{Local wind pressure coefficients for critical pressure taps}

Based on the aforementioned analysis about critical pressure distributions, two sets of strategically

critical pressure taps around hip and ridge corners, and on eaves around valleys, where larger peak suction appears among all pressure taps and tested models, are examined.

Results of only a single critical model for each type of buildings are displayed in Figs. 14 and 15, neglecting the horizontal aspect ratio effects. Note that to obtain an effective comparison, a rotation for rectangular models was made as depicted by the model sketches in Figs. 14 and 15. Under this updated model orientations, the measured wind directions for rectangular buildings are converted from $0^{\circ}$ to $90^{\circ}$ and from $270^{\circ}$ to $360^{\circ}$.

In terms of hip and ridge corners (shown in Fig. 14), the critical wind directions appear around $45^{\circ}$, for rectangular- and complex-roofed buildings. Moreover, the most critical pressure coefficient occurs on the rectangular gable roof, exceeding -4 . Hip roofs with L-, T-shaped and rectangular plans perform similarly in most cases, except those with non-rectangular plan views under the wind directions between $80^{\circ}$ and $160^{\circ}$. The differences indicate the considerable impact of the downwind roof block of the T-shaped model under these wind directions. In addition, mean and peak pressures vary with similar trends like those findings of rectangular hip roofs presented by Ahmad and Kumar (2002).

For the roof eaves around roof valleys, as shown in Fig. 15, considerable building plan impacts on wind pressures are observed, comparing rectangular and complex roofs. Wind pressure coefficient (uplift) of -3.5 occurs on the complex buildings, around the $45^{\circ}$ wind direction, which exceeds that on the rectangular hip roof by as large as $70 \%$. For most wind directions, the pressure trends of L- and T-shaped models are similar. Also, different pressure trends with smaller magnitudes (suction) are 
found for the gable roof.

\section{Characteristics of Area-averaged Wind Pressure Coefficients}

Following the previously presented critical local pressure variations associated with the safety of

local roof components and cladding, area-averaged loads are significant for roof sheathings, accounting

for both spatial variation and correlation effects of area wind pressures (Lin and Surry 1998). Therefore,

the results of peak area-averaged loads on both rectangular and non-rectangular models for all wind

directions were analyzed.

Referring to the specified guidelines of ASCE-7 (2010), the uniform zone size (z) of edge zones

was determined as $1 \mathrm{~m}$ in full scale controlled by the product of 0.1 times the width $(10 \mathrm{~m})$ of each 
Figure 18 presents area-averaged pressure results of the rectangular gable and hip roofs. Naturally,

with increasing the tributary area, all area-averaged pressure coefficients decrease, especially for the gable roof with a notable reduction. Roof shape influences on area-averaged pressure trends are clear for gable and hip roofs. More considerable local and area-averaged suction appears in all four zones of gable roofs. Minimal horizontal aspect ratio effects are presented for hip roofs, where the result trends are similar and ranges are rather narrow.

For L-shaped buildings, results of representative three models are presented in Fig. 19, including the comparable results of rectangular gable- and hip-roofed models for similar roof zones. Several interesting observations can be made compared with previous rectangular cases.

(1) Regarding Zone 1 on both outside and inside roof surfaces, similar pressure trends and values of L-shaped models can be found, which also agree with those of the rectangular hip roof. In comparison with the rectangular gable roof, lower suction for small tributary areas is found on rectangular and L-shaped models with hip roofs.

(2) Regarding Zone 2 along roof eave, more considerable suction on areas up to around $3 \mathrm{~m}^{2}$ is observed on inside roof surfaces of L-shaped roofs. On the contrary, smaller suction is found on both rectangular hip and outside surfaces of L-shaped roofs. Furthermore, the area-averaged results of the rectangular gable roof are critical for small tributary areas near roof corners. With the effective area increasing, these pressures for the gable roof decrease rapidly.

(3) Another critical roof region is Zone 2 along ridge/hip, in which discrepancies are observed. First, the suction is weakened along the inside surfaces, as observed previously. Second, the area-averaged results are shown as two groups - pressure coefficients are reduced on the shorter roof blocks (Blocks A of models with $L: W=7: 7$ and 9:7), especially for the results of inside surfaces. This 
indicates that both local and area-averaged wind pressures along the hip and ridge lines on the short blocks (Block A) are affected by other building blocks significantly. In fact, the most critical local and area-averaged suction also appears along the ridge on the rectangular gable roof.

(4) Considering Zone 2 of gable/hip end, suction results of all models with hip roofs perform similarly, but values are much smaller than those for the gable roof case.

The area-averaged pressures of T-shaped buildings are presented in Fig. 20, also divided into several different roof zones (e.g., Zone 1, Zone 2-eave), roof surfaces (Outside and Inside) and components (i.e., Components C, D and E). Note that rectangular models with gable and hip roofs and an L-shaped model $(L: W=9: 7)$ act as comparisons and references to investigate the performance of T-shaped models. Through the comprehensive comparisons, it is seen that for Zone 1, Zone 2 along roof eave and Zone 2 along ridge/hip on outside roof surfaces, T-shaped models perform quite similarly to the L-shaped cases, including the critical values and result patterns. However, regarding the inside roof ridge and hip lines, more fluctuating results indicate more influences induced by the more complex building plans. The result ranges for different components and buildings are wider. Similar wide ranges of results are also observed for Zone 2 along the gable/hip end. Therefore, for peak area-averaged pressure coefficients, T-shaped models are similar to the L-shaped cases, except for moderate fluctuations along inside ridge and hip lines, and hip-end edges.

Through this process, the effects of roof shape and building plan appear to make a significant difference on area-averaged loads. The aspect ratio impacts are clear only for Zone 2 along ridge/hip lines on the short blocks (Block A) of L-shaped roofs. The results of T-shaped plans keep their general agreement with those of the L-shaped cases. 


\title{
Comparisons with Wind Code and Standard Provisions
}

\author{
In this section, wind load provisions of ASCE-7 (2010) are selected to perform the comparisons
} with the current experimental results, to evaluate the suitability of the design wind loads applied to Land T-shaped buildings. It must be pointed out that there are no provisions for complex L- and T-shaped roofs, so the rectangular roof specified in wind load code (ASCE-7 2010) has been used for comparison purposes. As mentioned previously, due to the various referenced requirements of the wind codes/standards and the wind tunnel tests, including the referenced wind velocity, upstream terrain simulations etc., the presented results of wind tunnel tests in this section have been transformed into the equivalent design wind pressure coefficients, $(G C p)_{\mathrm{eq}}$ as introduced in Eq. (5).

In ASCE-7 (2010), the zone size (z) is mainly associated with mean roof heights and least horizontal dimensions, etc. However, it is questionable to determine a suitable "least horizontal dimension" for L- and T-shaped buildings between " $L+L$ ', $W$ ' for certain entire building dimensions and "w" for certain local component dimension as labeled in Fig. 21 (e). Therefore, both specified pressure coefficients and the zone size in ASCE-7 (2010) were evaluated.

Figure 21 shows the most critical area-averaged pressure coefficients for different roof zones on rectangular and complex buildings, as a good supplement. Roof zone sizes computed by dimension " $W$ " vs " $L+L$ " and " $w$ " are considered and plotted together to investigate the effectiveness of their performance. Note that L- and T-shaped buildings with larger " $W$ " and " $L+L$ " " are selected to act the examples, since their zone sizes (z) determined by " $W$ " or " $L+L$ "” are larger enough than those computed by fixed " $w$ ", so that the comparison will be clear.

Results obtained from " $W$ " vs " $L+L$ " " and " $w$ " differ evidently, particularly on the interior zone (Zone 1), as shown in Fig. 21 (a). Since an adopted relatively larger reference dimension " $W$ ” or 
" $L+L$ "” leads to a narrower interior zone with smaller local and area suction, these area pressures (Zone 1) exceed moderately and nearly match the code-specified wind pressure coefficients, compared with those determined by " $w$ ". However, for rectangular models, the ASCE-7 (2010) underestimates the measured wind pressure coefficients significantly, especially those for small areas, as also mentioned by Vickery et al. (2011).

For the case of Zone 2 (Edge zones), different zone sizes calculated from " $W$ " vs " $L+L$ "” and " $w$ " hardly affect the area-averaged pressures, as both the edge and end zone sizes determined by these two methods can envelop the area associated with critical measured test data. Considering the variation of area pressure coefficients, Fig. 21 (b) depicts the results for Zone 2 along roof end, where ASCE-7 wind loading provisions cover all measured data of buildings with hip roofs leading to an uneconomical result. However, for the gable roof, the wind standard performs inadequately for tributary areas less than about $4 \mathrm{~m}^{2}$. Considering Zone 2 along roof eave as shown in Fig. 21 (c), generally most results are covered by the standard, except those underestimated local pressures of rectangular gable roofs with small effective areas. With an increase in tributary area, area-averaged pressure coefficients of the gable roof drop rapidly and become less than the design values. Furthermore, Fig. 21 (d) presents a comparison of critical experimental pressure coefficients with those prescribed by the standard for Zone 2 around roof ridge/hip. ASCE-7 (2010) provisions underestimate the tested results for gable and hip roofs with tributary areas ranging from $2 \mathrm{~m}^{2}$ to $10 \mathrm{~m}^{2}$, including rectangular and complex plans.

In general, the current American wind standard (ASCE-7 2010) performs adequately for hip-roofed rectangular and complex shape buildings, except for Zone 1 for rectangular buildings and Zone 2 along ridge/hip with larger areas for rectangular and complex cases. Moreover, the design wind 
pressure coefficients of ASCE-7 (2010) for Zone 2 along hip ends are significantly overestimated.

Finally, it is more suitable to utilize the entire L- or T-shaped roof dimensions such as " $W$ " or " $L+L$ "”, as opposed to the rectangular section only, to determine the least horizontal dimension of complex hip roofs.

\section{Summary and Conclusions}

Basic aerodynamic features, local and area-averaged wind loads on rectangular, L- and T-shaped plan-view buildings with gable or hip roofs sloped at 4:12 have been determined through comprehensive wind tunnel experiments. Moreover, the applicability of current wind provisions (ASCE-7 2010) for such geometries has also been evaluated.

The most significant parameters, which affect local and area-averaged wind loads on roofs, are the shape of the roof (gable and hip) and the building plan (rectangular, L- and T-shaped). Considering the roof shape (gable and hip roofs) effect, hip roofs including rectangular and complex plans perform quite differently from the rectangular gable roof when subjected to wind and incur smaller local and area-averaged suction. Regarding the building plan (rectangular, L- and T-shaped) effect, it is recognized that wind load distributions on L- and T-shaped roofs are influenced by the wind separation from leading edges and by the upwind or downwind roof blocks. As a result, both similarities and differences exist on non-rectangular roofs under variable wind conditions, compared with rectangular cases. These can be summarized as follows:

(1) When re-entrant corners of L-shape buildings are on the leeward sides, minimal differences in pressure coefficients of upwind roof blocks are found between L-shaped and rectangular buildings with hip roofs, for normal and oblique wind directions.

(2) For the wind directing towards roof valleys, distinctive wind pressure characteristics for both 
upwind and downwind roof blocks are observed. Specifically, regarding the wind acting normally on the hip-end face $\left(\theta=0^{\circ}\right.$ or $\left.90^{\circ}\right)$, extreme suction decreases by almost $30 \%$ and $40 \%$ along the respective leading edge and the leeward hip line of the hip-end block on the side of the building re-entrant corner. However, more intensive negative pressure coefficients appear along the roof eaves near the roof valleys, especially for an oblique wind azimuth of about $45^{\circ}$.

(3) In general, T-shaped buildings act to some extent like those of L-shaped plans in most cases, with similar wind conditions.

Furthermore, length-to-width aspect ratio (ranging from 1.0 to 3.0) effects have also been found moderate for nearly all roof and building configurations, except for area-averaged loads for Zone 2 along ridge/hip lines on short roof blocks of non-rectangular roofs.

ASCE-7 (2010) is adequate for L- and T-shaped hip roofs, except for Zone 2 along ridge/hip with large areas, in which current measured results exceed the code-specified wind pressure coefficients. Finally, it is better to utilize the entire L- or T-shaped roof dimensions such as " $W$ " or " $L+L$ ", as opposed to the rectangular section only, to determine the least horizontal dimension of complex hip roofs for use in the definition of roof zones.

\section{Acknowledgments}

The support provided by 111 Project of China (B13002) and China Scholarship Council, China (CSC201507090037) for the first author's study at Concordia University (November 2015 - May 2017) is gratefully acknowledged.

\section{References}

Ahmad, S., and Kumar, K. (2002). "Effect of geometry on wind pressures on low-rise hip roof buildings.” J. Wind. Eng. Ind. Aerodyn., 90(7), 755-779.

AIJ (Architectural Institute of Japan). (1993). AIJ Recommendations for Loads on Buildings, Tokyo, 
Japan.

Alrawashdeh, H., and Stathopoulos, T. (2015). "Wind pressures on large roofs of low buildings and wind codes and standards." J. Wind. Eng. Ind. Aerodyn., 147, 212-225.

ASCE-7 (American Society of Civil Engineers). (2010). "Minimum design loads for building and other structures." ASCE/SEI 7-10, Reston, Va.

Case, P. C., and Isyumov, N. (1998). "Wind loads on low buildings with 4:12 gable roofs in open country and suburban exposures.” J. Wind. Eng. Ind. Aerodyn., 77-78, 107-118.

CEN (European Committee for Standardization). (2004). "Eurocode 1: Actions on structures — General actions_-Part 1.4: Wind actions.”prEN 1991-1-4, Brussels.

Cope, A. D., Gurley, K. R., Gioffre, M. and Reinhold, T. A. (2005). "Low-rise gable roof wind loads: characterization and stochastic simulation.” J. Wind. Eng. Ind. Aerodyn., 93(9), 719-738.

Deaves, D. M. (1981). “Computations of wind flow over changes in surface roughness.” J. Wind. Eng. Ind. Aerodyn., 7(1), 65-94.

Ding, J. and Chen, X. (2015). "Moment-based translation model for hardening non-Gaussian response processes.” J. Eng. Mech., 14210.1061/(ASCE)EM.1943-7889.0000986, 06015006.

ESDU (Engineering Science Data Unit). (1982). "Strong winds in the atmospheric boundary layer. Part 1. Mean-hourly wind speeds.” Data Item 82026, London, U.K.

Gavanski, E., Kordi, B., Kopp, G. A., and Vickery, P. J. (2013). "Wind loads on roof sheathing of houses." J. Wind. Eng. Ind. Aerodyn., 114, 106-121.

Gavanski, E., and Uematsu, Y. (2014). "Local wind pressures acting on walls of low-rise buildings and comparisons to the Japanese and US wind loading provisions." J. Wind. Eng. Ind. Aerodyn., 132, $77-91$.

Gioffrè, M., Gusella, V., and Grigoriu, M. (2000). "Simulation of non-Gaussian field applied to wind pressure fluctuations.” Probab. Eng. Mech., 15(4), 339-345.

Grigoriu, M. (1984). “Crossings of non-Gaussian translation processes.” J. Eng. Mech., .1061/(ASCE)0733-9399(1984)110:4(610), 610-620.

Holmes, J. D. (1981). "Non-gaussian characteristics of wind pressure fluctuations.” J. Wind. Eng. Ind. Aerodyn., 7(1), 103-108.

Holmes, J. D. (1983). “Wind loads on low - rise buildings - a review.” Rep., Div. of Build. Res., Commonwealth Scientific and Industrial Research Organization (CSIRO), Melbourne, Australia.

Holmes, J. D. (1994). "Wind pressures on tropical housing." J. Wind. Eng. Ind. Aerodyn., 53(1-2), 105-123. 
Holmes, J. D., and Cochran, L. S. (2003). "Probability distributions of extreme pressure coefficients.” J. Wind. Eng. Ind. Aerodyn., 91(7), 893-901.

Irwin, P. A. (2006). "Exposure categories and transitions for design wind loads." J. Struct. Eng., 10.1061/(ASCE)0733-9445(2006)132:11(1755), 1755-1763.

Kanda, M., and Maruta, E. (1993). "Characteristics of fluctuating wind pressure on long low-rise buildings with gable roofs.” J. Wind. Eng. Ind. Aerodyn., 50, 173-182.

Kikuchi, H., Tamura, Y., Hibi, K., and Suganuma, S. (2001). "Local pressures acting on low-rise and middle-rise buildings with 1-shape plan.” Proc., 5th Asia-Pacific Conf. on Wind Engineering, International Association for Wind Engineering.

Kumar, K. S., and Stathopoulos, T. (2000). "Wind loads on low building roofs: A stochastic perspective.” J. Struct. Eng., 10.1061/(ASCE)0733-9445(2000)126:8(944), 944-956.

Li, Q. S., Calderone, I., and Melbourne, W. H. (1999). "Probabilistic characteristics of pressure fluctuations in separated and reattaching flows for various free-stream turbulence." J. Wind. Eng. Ind. Aerodyn., 82(1-3), 125-145.

Lin, J. X., Surry, D., and Tieleman, H. W. (1995). "The distribution of pressure near roof corners of flat roof low buildings." J. Wind. Eng. Ind. Aerodyn., 56(2-3), 235-265.

Lin, J. X., and Surry, D. (1998). "The variation of peak loads with tributary area near corners on flat low building roofs." J. Wind. Eng. Ind. Aerodyn., 77-78, 185-196.

Liu, M., Chen, X., and Yang, Q. (2017). "Estimation of peak factor of non-Gaussian wind pressures by improved moment-based Hermite model.” J. Eng. Mech., 10.1061/(ASCE)EM.1943-7889.0001233.

Meecham, D., Surry, D., and Davenport, A. G. (1991). "The magnitude and distribution of wind-induced pressures on hip and gable roofs." J. Wind. Eng. Ind. Aerodyn., 38(2-3), 257-272.

NBCC (National Building Code of Canada). (2015). User's Guide-NBC 2015, Structural Commentaries (Part 4), Canadian Commission on Buildings and Fire Codes, National Research Council of Canada, Ottawa.

Nie, S., Zhou, X., Tao, L., and Zhou, T. (2016). "Wind tunnel test and numerical analysis on wind load characteristics of plan T-shaped low-rise buildings." J. Archit. Civ. Eng., 31-40 (in Chinese).

Peng, X., Yang, L., Gavanski, E., Gurley, K., and Prevatt, D. (2014). “A comparison of methods to estimate peak wind loads on buildings.” J. Wind. Eng. Ind. Aerodyn., 126, 11-23.

Sadek, F., and Simiu, E. (2002). "Peak non-Gaussian wind effects for database-assisted low-rise building design.” J. Eng. Mech., 10.1061/(ASCE)0733-9399(2002)128:5(530), 530-539. 
St. Pierre, L. M., Kopp, G. A., Surry, D., and Ho, T. C. E. (2005). "The UWO contribution to the NIST aerodynamic database for wind loads on low buildings: Part 2. Comparison of data with wind load provisions." J. Wind. Eng. Ind. Aerodyn., 93(1), 31-59.

Stathopoulos, T. (1980). "PDF of wind pressures on low-rise buildings." J. Struct. Div., 106(5), 973-990.

Stathopoulos, T. (1984a). "Wind loads on low-rise buildings: a review of the state of the art." Eng. Struct., 6(2), 119-135.

Stathopoulos, T. (1984b). "Design and fabrication of a wind tunnel for building aerodynamics." $J$. Wind. Eng. Ind. Aerodyn., 16(2-3), 361-376.

Stathopoulos, T. (2003). "Wind loads on low buildings: in the wake of Alan Davenport's contributions.” J. Wind. Eng. Ind. Aerodyn., 91(12-15), 1565-1585.

Stathopoulos, T., and Luchian, H. D. (1990). "Wind pressures on buildings with multi-level roofs." $J$. Wind. Eng. Ind. Aerodyn., 36, 1299-1308.

Stathopoulos, T., and Mohammadian, A. R. (1986). "Wind loads on low buildings with mono-sloped roofs.” J. Wind. Eng. Ind. Aerodyn., 23, 81-97.

Stathopoulos, T., and Saathoff, P. (1991). "Wind pressure on roofs of various geometries.” J. Wind. Eng. Ind. Aerodyn., 38(2-3), 273-284.

Stathopoulos, T., and Surry, D. (1983). "Scale effects in wind tunnel testing of low buildings." J. Wind. Eng. Ind. Aerodyn., 13(1-3), 313-326.

Stathopoulos, T., and Wang, K. (2001). "Wind pressure provisions for gable roofs of intermediate roof slope." Wind Struct., 4(2), 119-130.

Stathopoulos, T., and Zhou, Y. (1993). “Computation of wind pressures on L-shaped buildings.” $J$. Eng. Mech., 10.1061/(ASCE)0733-9399(1993)119:8(1526), 1526-1541.

Tao, L., Huang, P., Gu, M., and Quan, Y. (2011). "Wind loading characteristics of low-rise buildings roof with L-shape plan.” J. Tongji Univ. (Natural Science), 39(11), 1586-1591 (in Chinese).

Uematsu, Y., and Isyumov, N. (1999). "Wind pressures acting on low-rise buildings.” J. Wind. Eng. Ind. Aerodyn., 82(1-3), 1-25.

Van de Lindt, J. W., Graettinger, A., Gupta, R., Skaggs, T., Pryor, S., and Fridley, K. J. (2007). "Performance of wood-frame structures during hurricane Katrina." J. Perform. Constr. Facil., 10.1061/(ASCE)0887-3828(2007)21:2(108), 108-116.

Vickery, P. J., Kopp, G. A., and TwisdaleJr., L. A. (2011). “Component and cladding wind pressures on hip and gable roofs: components to the US wind loading provisions." Proc., 13th Int. Conf. on 
Wind Engineering, ICWE 13, International Association for Wind Engineering.

586 Winterstein, S. R., and Kashef, T. (2000). "Moment-based load and response models with wind engineering applications.” J. Solar Energy Eng., 122(3), 122-128.

588 Xu, Y. L., and Reardon, G. F. (1998). "Variations of wind pressure on hip roofs with roof pitch." $J$. Wind. Eng. Ind. Aerodyn., 73(3), 267-284.

590 Yang, L., Gurley, K. R., and Prevatt, D. O. (2013). "Probabilistic modeling of wind pressure on low-rise buildings." J. Wind. Eng. Ind. Aerodyn., 114, 18-26.

592 Yang, Q., and Tian, Y. (2015). “A model of probability density function of non-Gaussian wind pressure with multiple samples.” J. Wind. Eng. Ind. Aerodyn., 140, 67-78. 


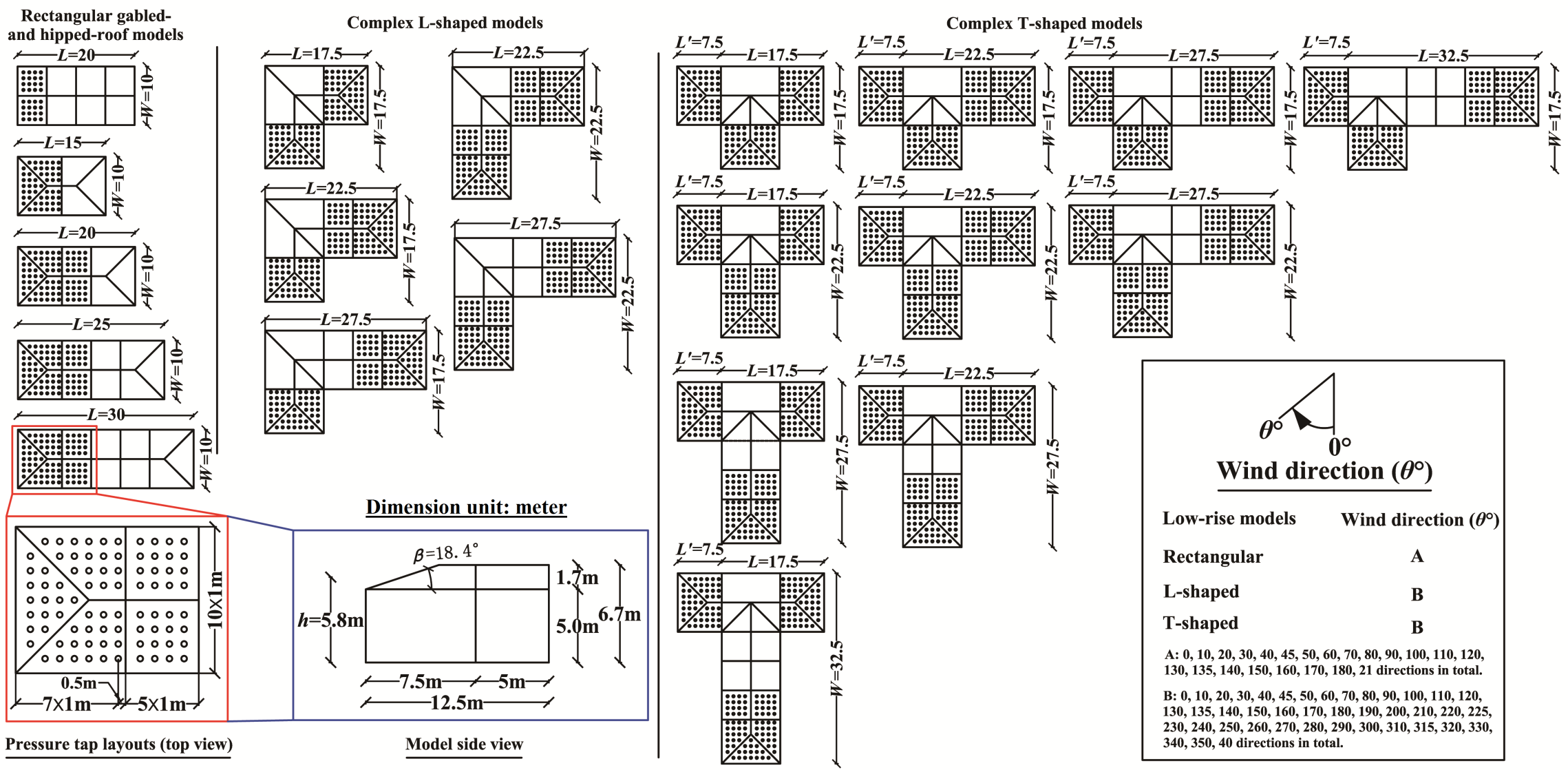

Fig. 1. Tested models: plan views, dimensions, pressure tap layouts and wind directions 

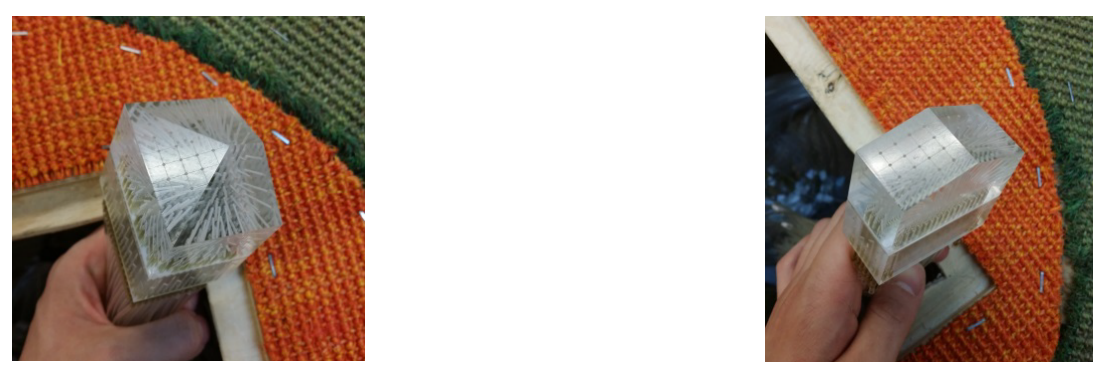

(a) Basic tested models with pressure taps

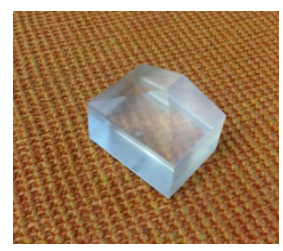

Hipped-end component

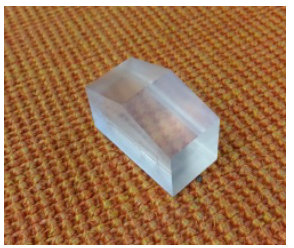

Gabled component

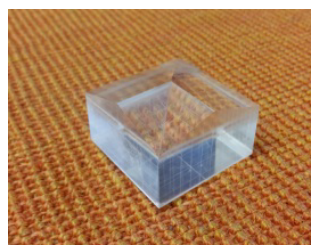

L-shaped valley component

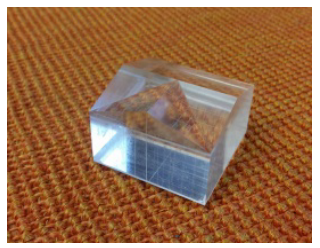

T-shaped valley component

(b) Component models without pressure taps
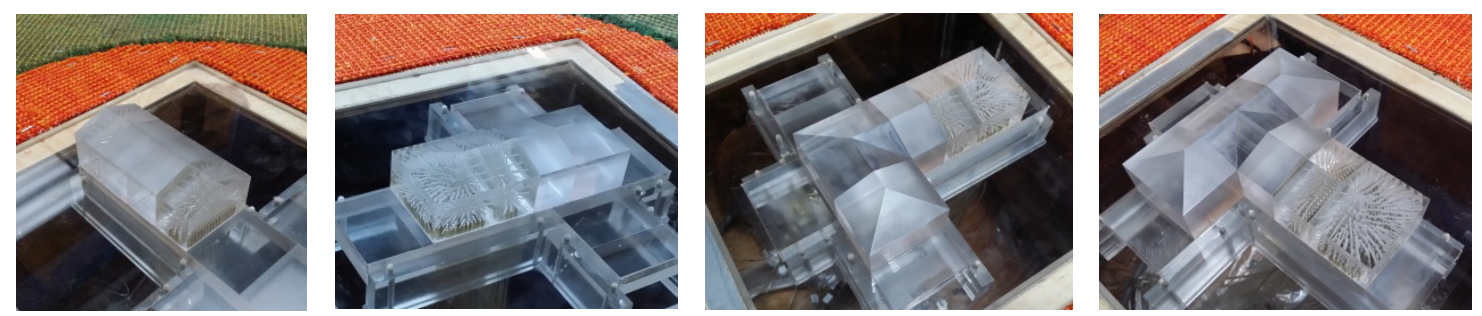

(c) Typical rectangular, L- and T-shaped models with gabled or hipped roofs as examples

Fig. 2. Typical building models tested in the wind tunnel 


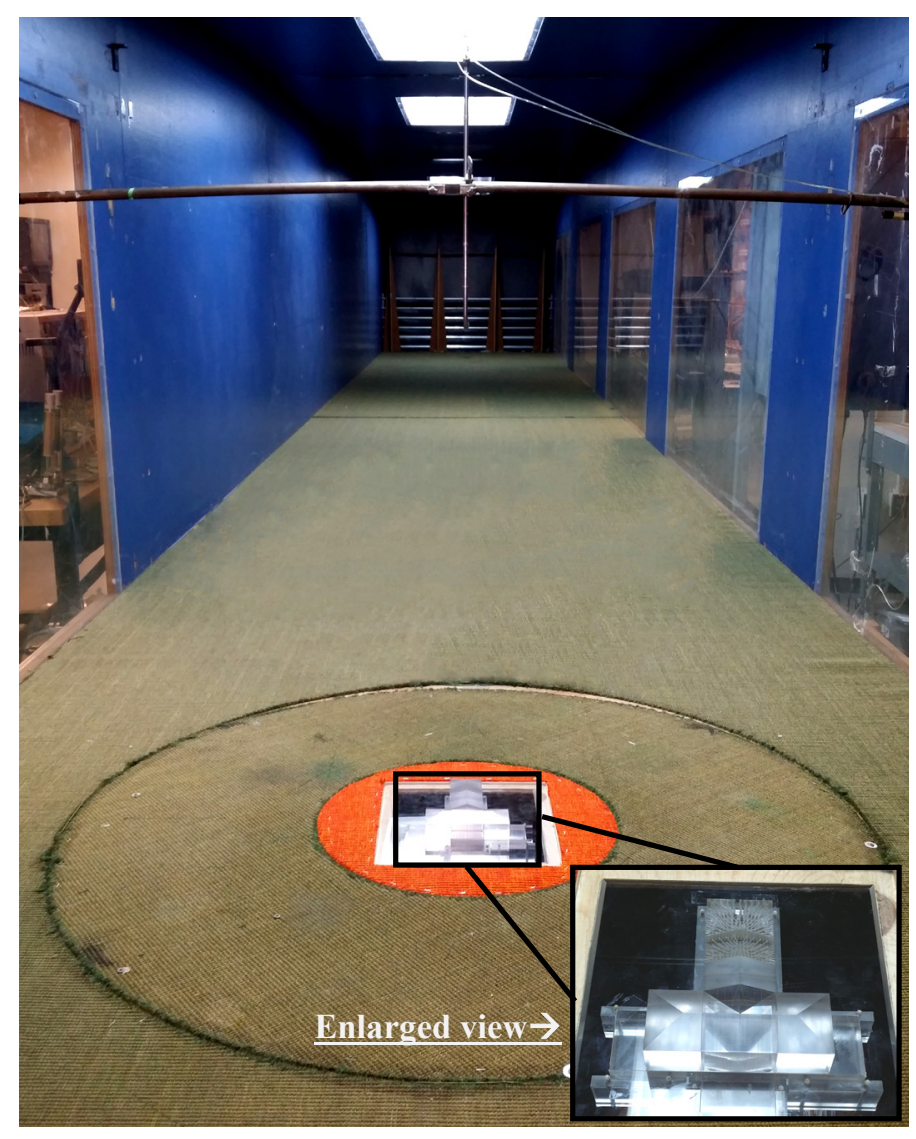

Fig. 3. Boundary layer wind tunnel at Concordia University (Front view) 


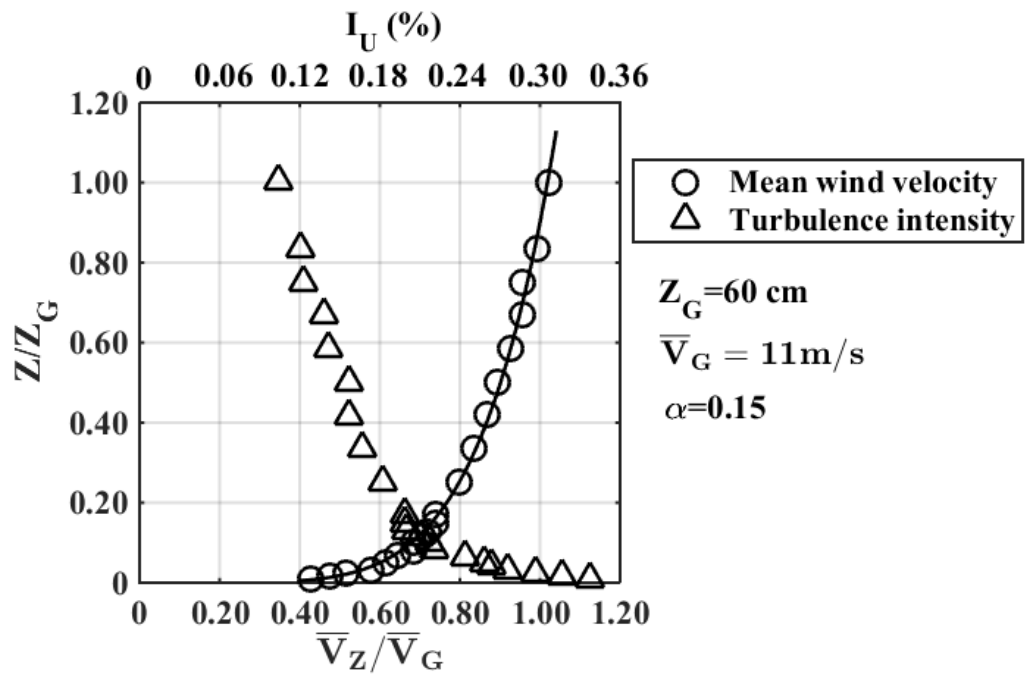

Fig. 4. Wind velocity and turbulence intensity profiles for open country terrain exposure 


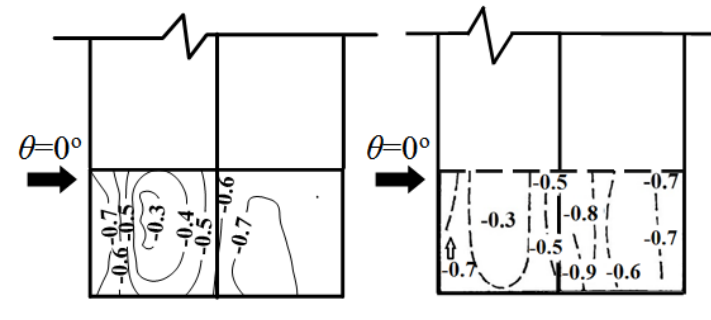

Present study

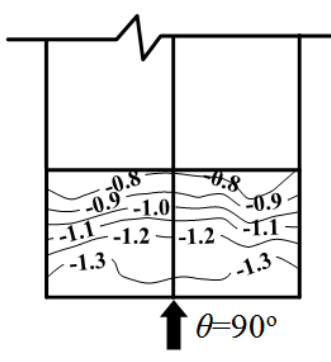

Present study

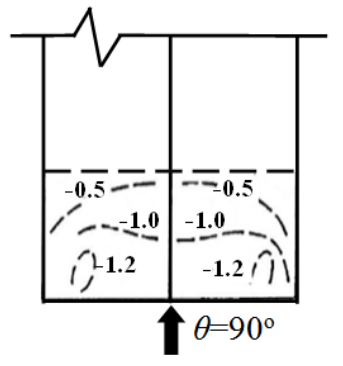

Holmes (1983)

Fig. 5. Mean wind pressure coefficient contours for gable roofs from present study and Holmes (1983) 

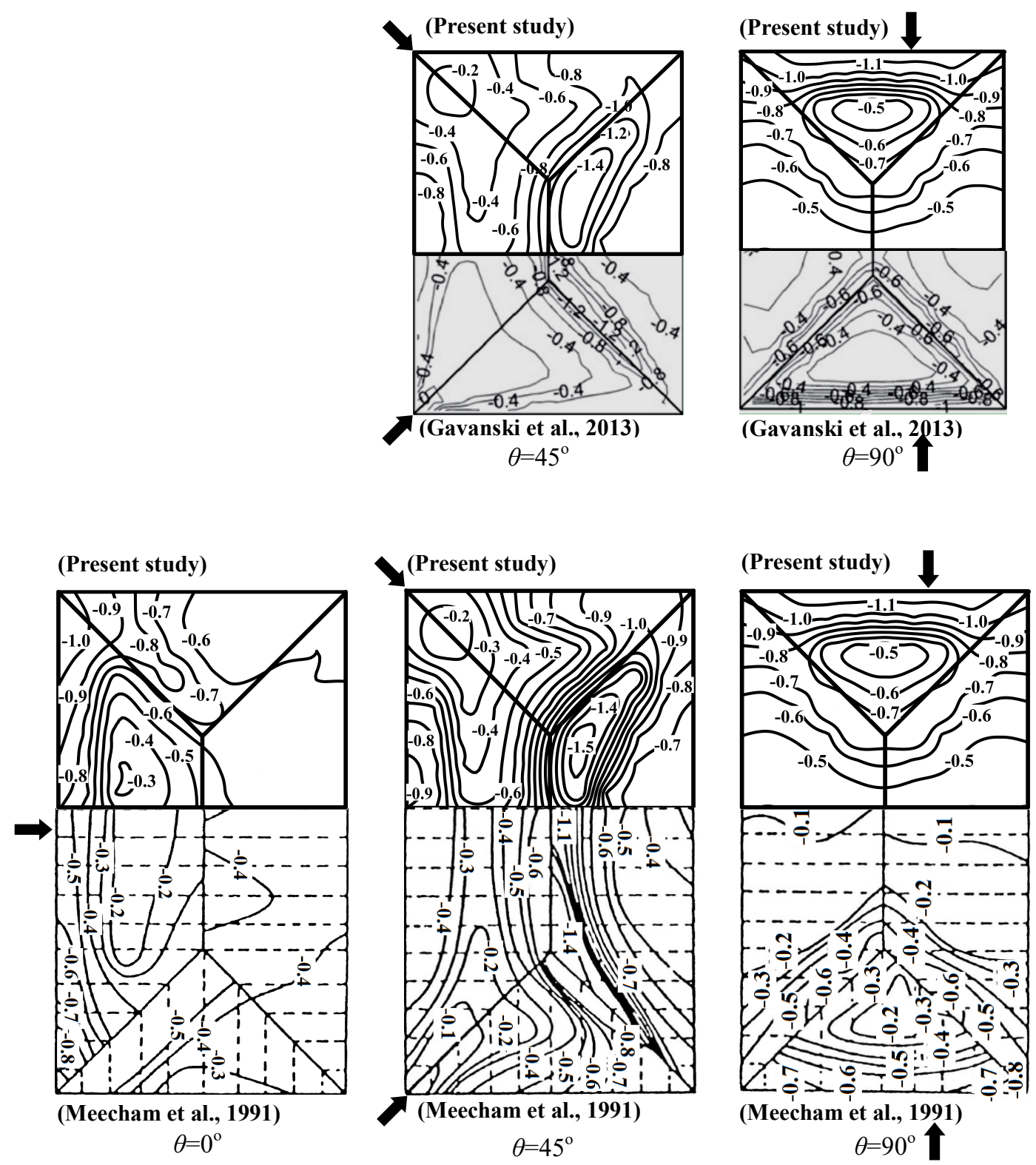

Fig. 6. Mean wind pressure coefficient contours for hip roofs from present study, Meecham et al. 


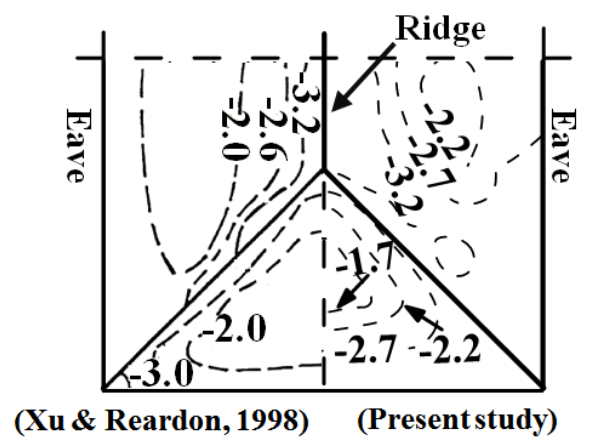

(a)

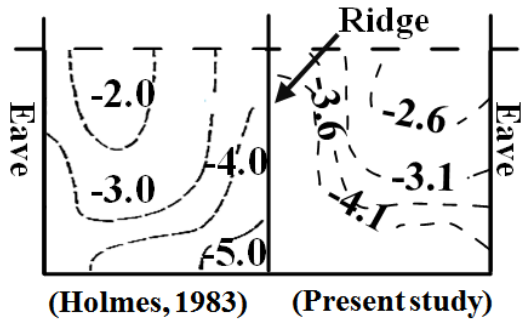

(b)

Fig. 7. Most critical wind pressure coefficient contours from present study, Holmes (1983) and Xu \&

Reardon (1998): (a) Rectangular hip roofs, (b) Rectangular gable roofs 


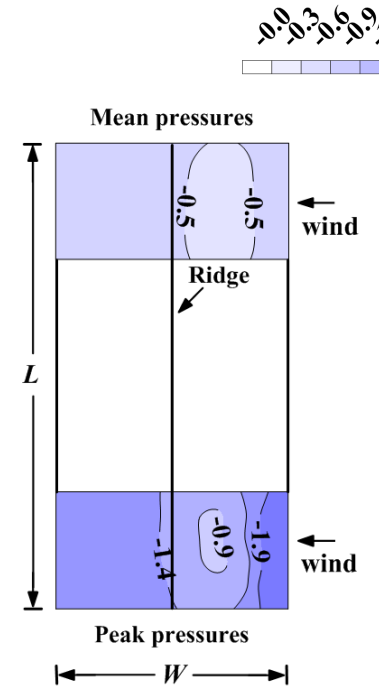

$L: W=4: 2, \theta=0^{\circ}$

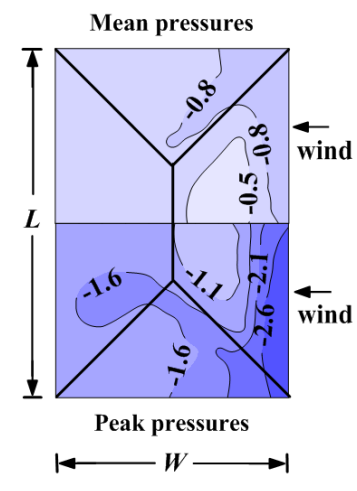

$L: W=3: 2, \theta=0^{\circ}$

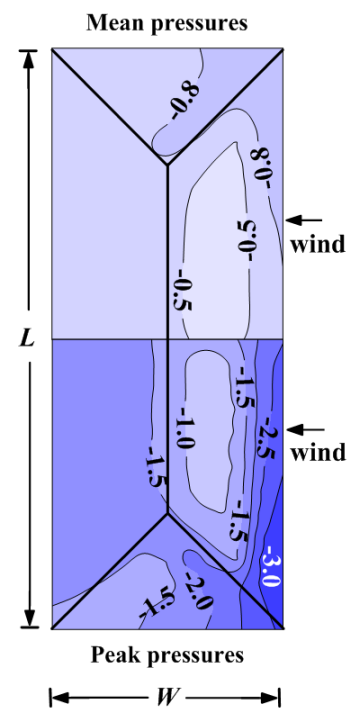

$L: W=5: 2, \theta=0^{\circ}$
(Mean pressures)

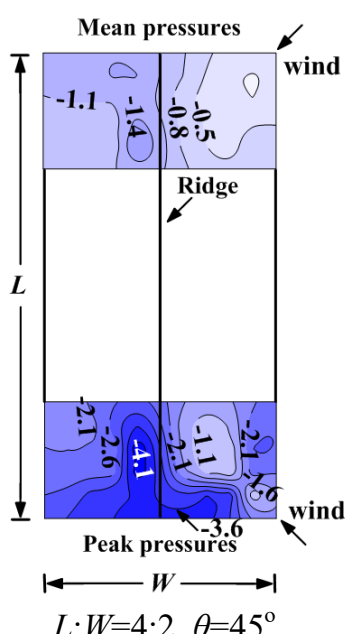

$L: W=4: 2, \theta=45^{\circ}$

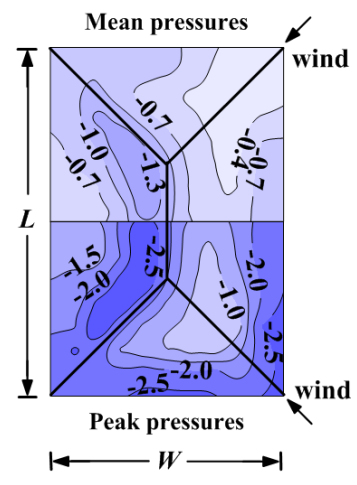

$L: W=3: 2, \theta=45^{\circ}$

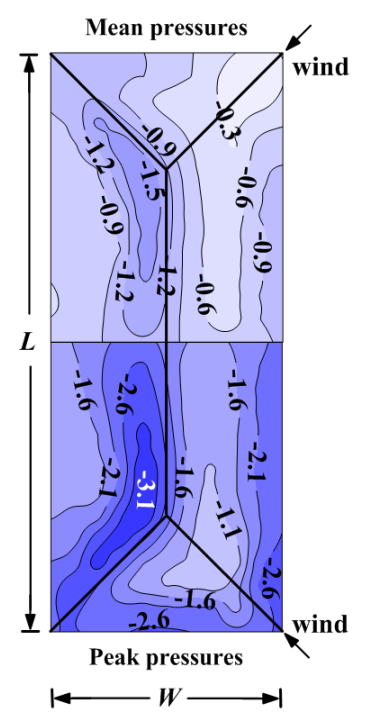

$L: W=5: 2, \theta=45^{\circ}$
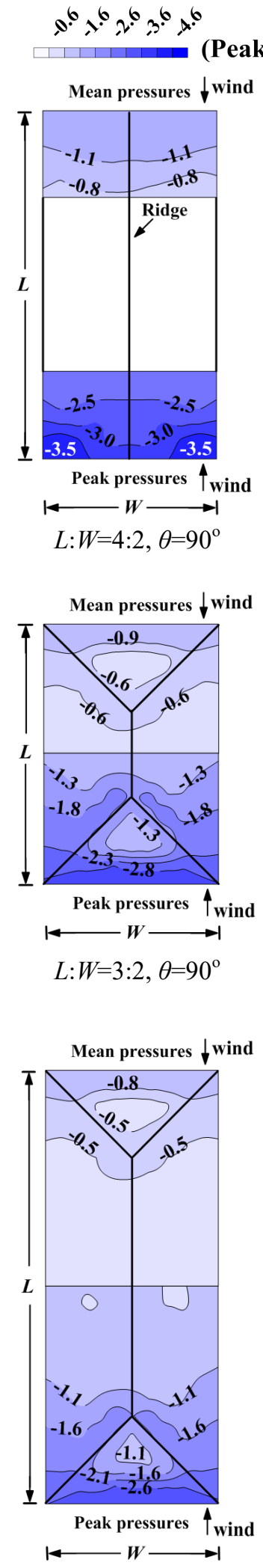

$L: W=5: 2, \theta=90^{\circ}$

Fig. 8. Pressure coefficient distributions on rectangular building roofs for different aspect ratios $(L: W)$; and different wind directions, $\theta\left(0^{\circ}, 45^{\circ}, 90^{\circ}\right)$ 


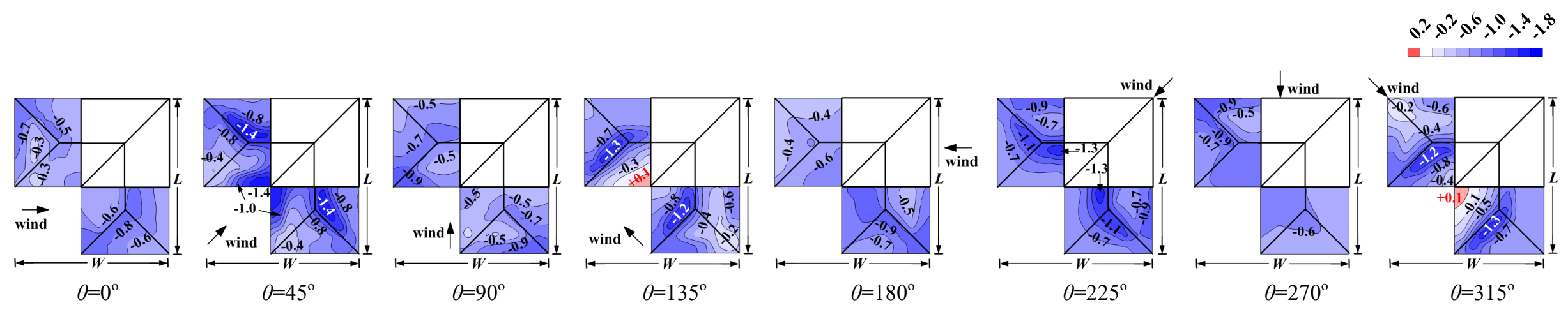

(a) $L \times W=17.5 \mathrm{~m} \times 17.5 \mathrm{~m}(L: W=7: 7)$
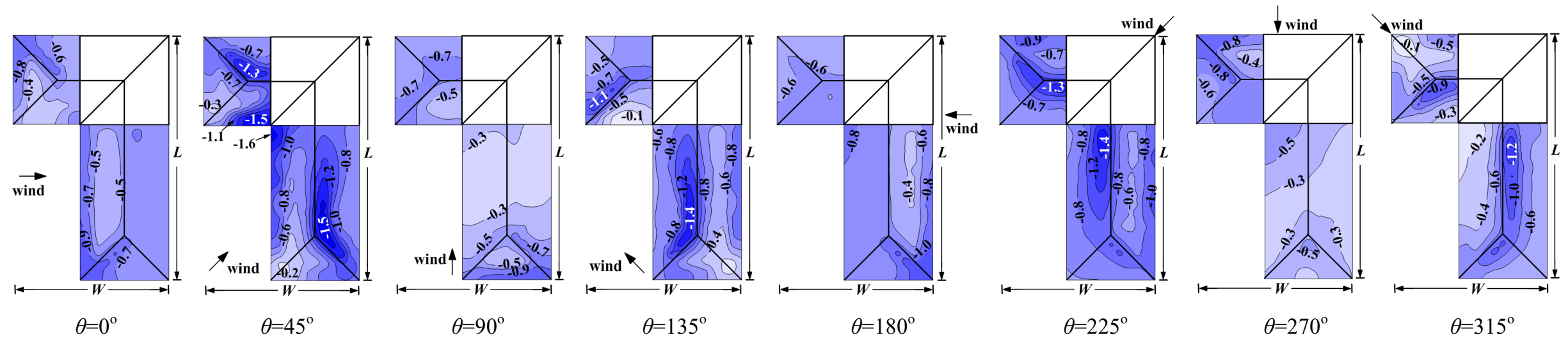

(b) $L \times W=27.5 \mathrm{~m} \times 17.5 \mathrm{~m}(L: W=11: 7)$

Fig. 9. Mean roof pressure coefficient distributions of L-shaped buildings for wind direction, $\theta$ of $0^{\circ}, 45^{\circ}, 90^{\circ}, 135^{\circ}, 180^{\circ}, 225^{\circ}, 270^{\circ}, 315^{\circ}$ 


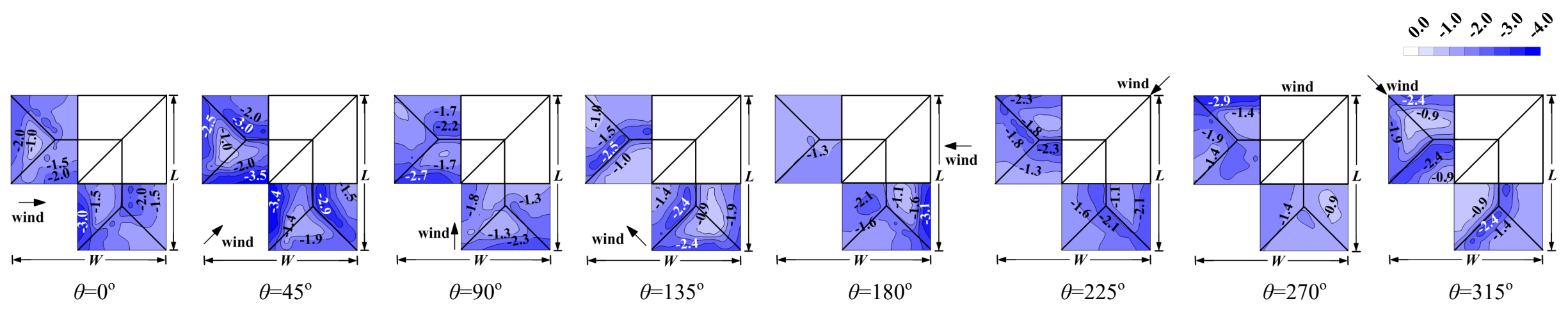

(a) $L \times W=17.5 \mathrm{~m} \times 17.5 \mathrm{~m}(L: W=7: 7)$
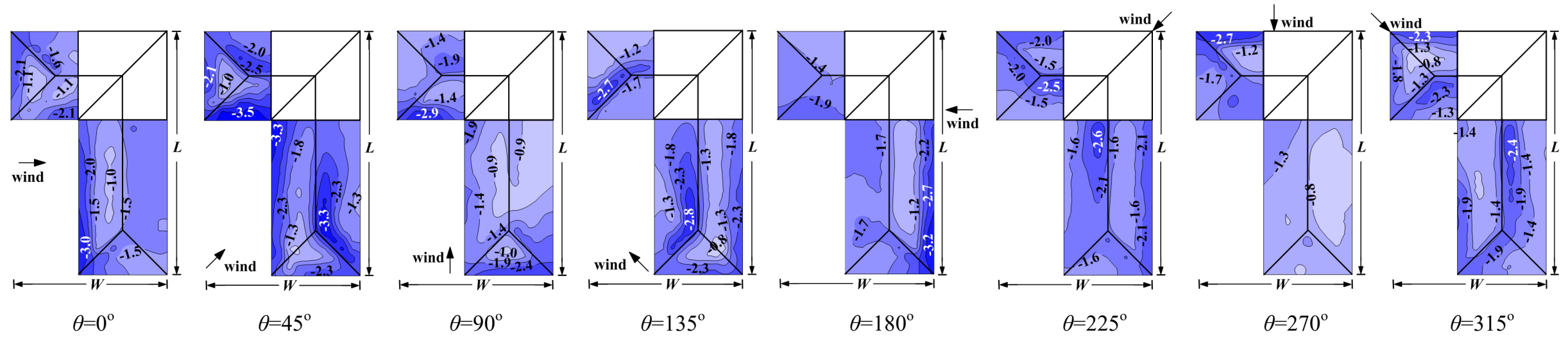

(b) $L \times W=27.5 \mathrm{~m} \times 17.5 \mathrm{~m}(L: W=11: 7)$

Fig. 10. Peak roof pressure coefficient distributions of L-shaped buildings for wind direction, $\theta$ of $0^{\circ}, 45^{\circ}, 90^{\circ}, 135^{\circ}, 180^{\circ}, 225^{\circ}, 270^{\circ}, 315^{\circ}$ 


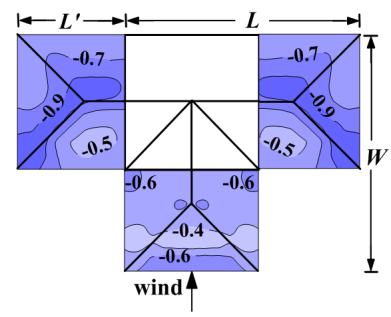

$\theta=0^{\circ}$

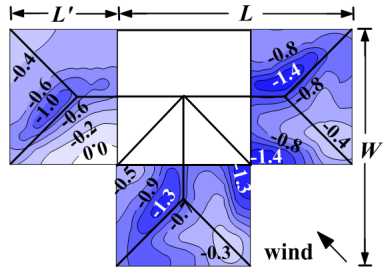

$\theta=45^{\circ}$

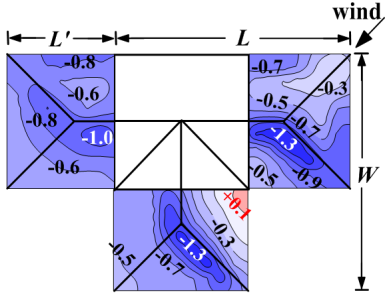

$\theta=135^{\circ}$

(a) $L \times L^{\prime} \times W=17.5 \mathrm{~m} \times 7.5 \mathrm{~m} \times 17.5 \mathrm{~m}\left(L: L^{\prime}: W=7: 3: 7\right)$

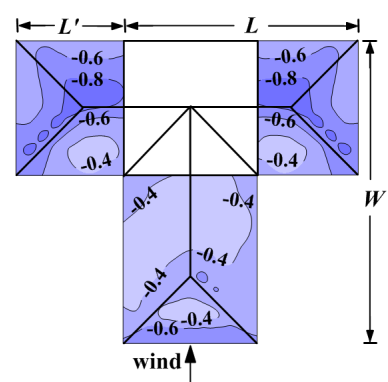

$\theta=0^{\circ}$

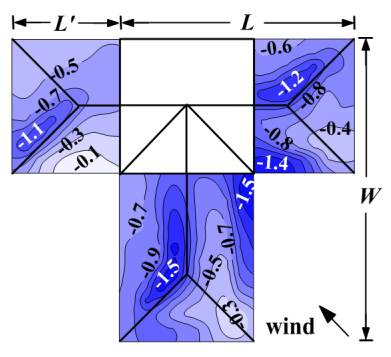

$\theta=45^{\circ}$

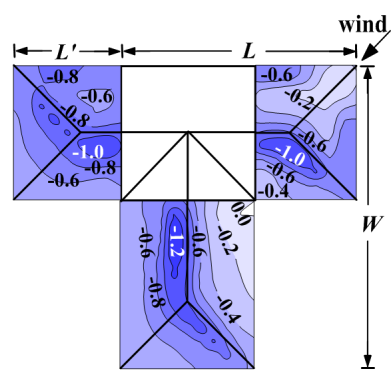

$\theta=135^{\circ}$

(b) $L \times L^{\prime} \times W=17.5 \mathrm{~m} \times 7.5 \mathrm{~m} \times 22.5 \mathrm{~m}\left(L: L^{\prime}: W=7: 3: 9\right)$

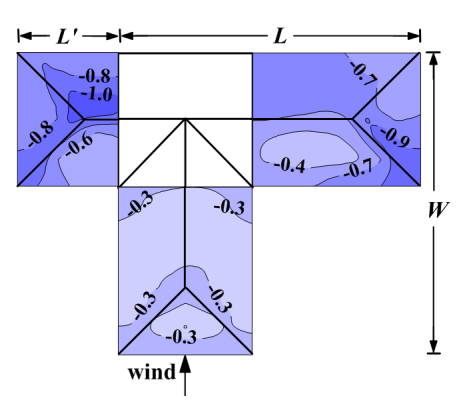

$\theta=0^{\circ}$

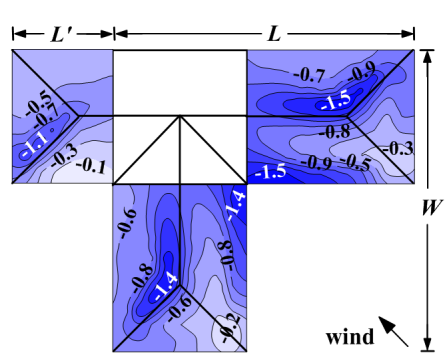

$\theta=45^{\circ}$

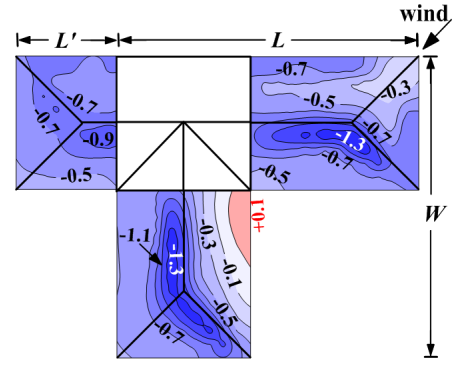

$\theta=135^{\circ}$

(c) $L \times L^{\prime} \times W=22.5 \mathrm{~m} \times 7.5 \mathrm{~m} \times 22.5 \mathrm{~m}\left(L: L^{\prime}: W=9: 3: 9\right)$

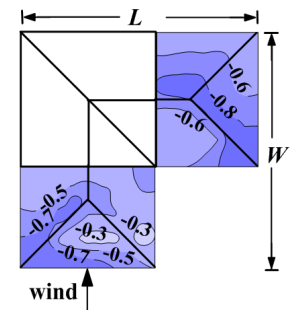

$\theta=0^{\circ}$

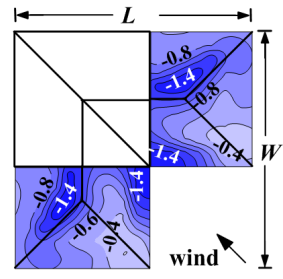

$\theta=45^{\circ}$

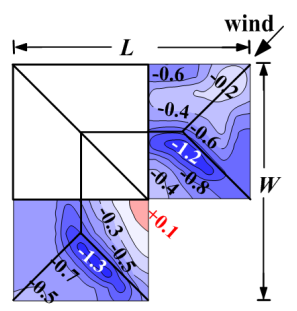

$\theta=135^{\circ}$

(d) $L \times W=17.5 \mathrm{~m} \times 17.5 \mathrm{~m}(L: W=7: 7)$

Fig. 11. Mean roof pressure coefficient distributions of T-shaped buildings for each aspect ratio, $L: L^{\prime}: W$, and wind direction, $\theta$ of $0^{\circ}, 45^{\circ}, 135^{\circ}$ 


\section{$0^{9}, x^{9}, x^{\circ}$}

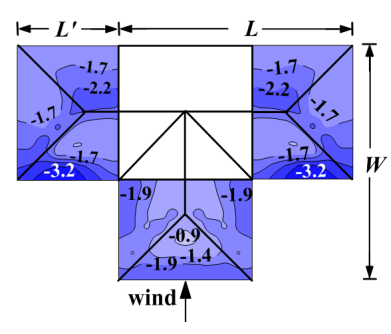

$\theta=0^{\circ}$

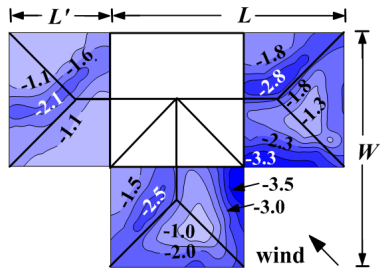

$\theta=45^{\circ}$

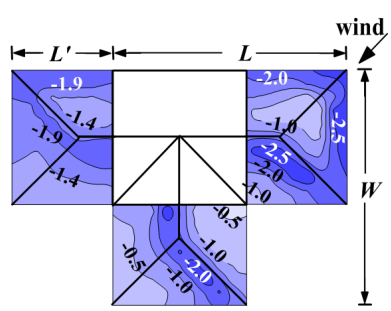

$\theta=135^{\circ}$

(a) $L \times L^{\prime} \times W=17.5 \mathrm{~m} \times 7.5 \mathrm{~m} \times 17.5 \mathrm{~m}\left(L: L^{\prime}: W=7: 3: 7\right)$

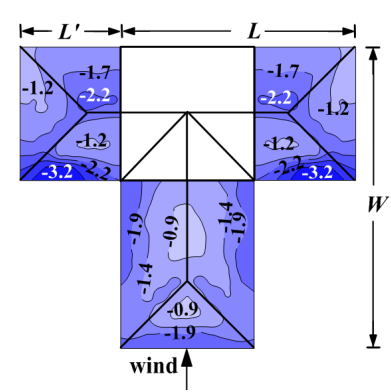

$\theta=0^{\circ}$

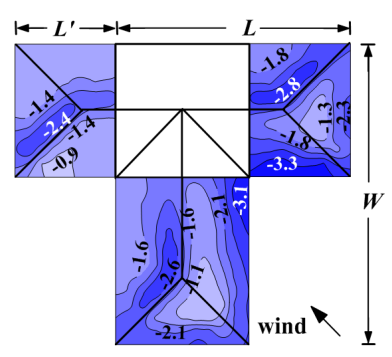

$\theta=45^{\circ}$

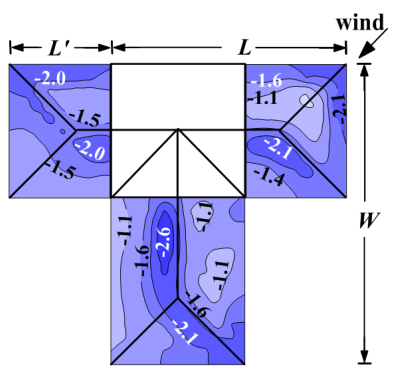

$\theta=135^{\circ}$

(b) $L \times L^{\prime} \times W=17.5 \mathrm{~m} \times 7.5 \mathrm{~m} \times 22.5 \mathrm{~m}\left(L: L^{\prime}: W=7: 3: 9\right)$

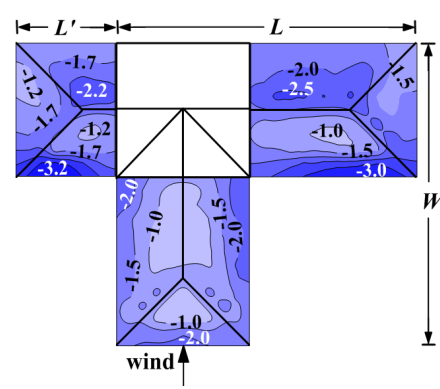

$\theta=0^{\circ}$

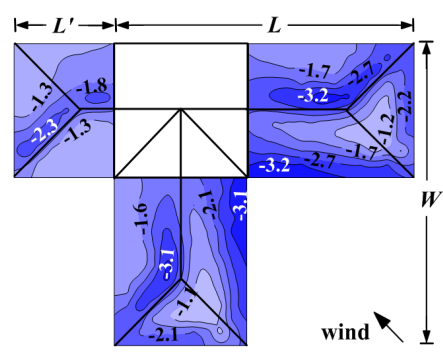

$\theta=45^{\circ}$

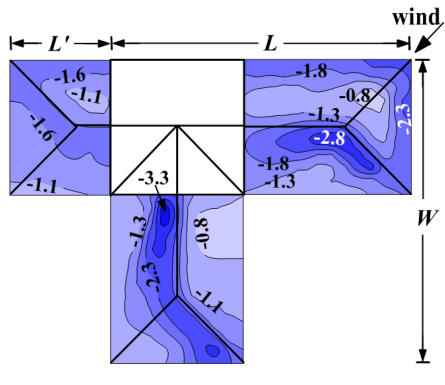

$\theta=135^{\circ}$

(c) $L \times L^{\prime} \times W=22.5 \mathrm{~m} \times 7.5 \mathrm{~m} \times 22.5 \mathrm{~m}\left(L: L^{\prime}: W=9: 3: 9\right)$

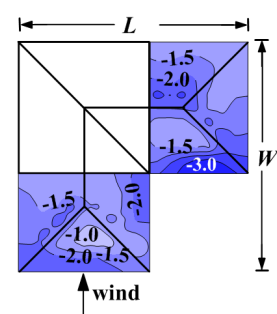

$\theta=0^{\circ}$

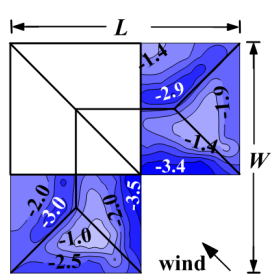

$\theta=45^{\circ}$

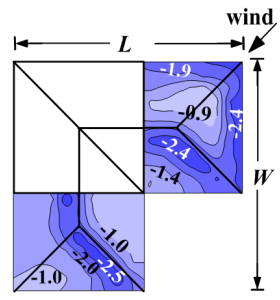

$\theta=135^{\circ}$

(d) $L \times W=17.5 \mathrm{~m} \times 17.5 \mathrm{~m}(L: W=7: 7)$

Fig. 12. Peak roof pressure coefficient distributions of T-shaped buildings for each aspect ratio, $L: L ': W$, and wind direction, $\theta$ of $0^{\circ}, 45^{\circ}, 135^{\circ}$ 


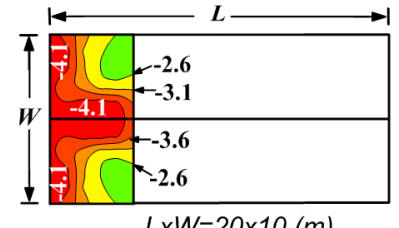

$\underline{L \times W=20 \times 10(m)}$

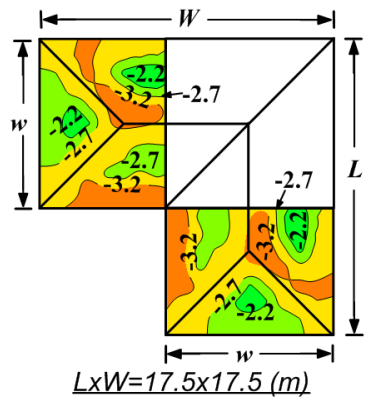

$\underline{L N W=175 \times 175(\mathrm{~m})}$
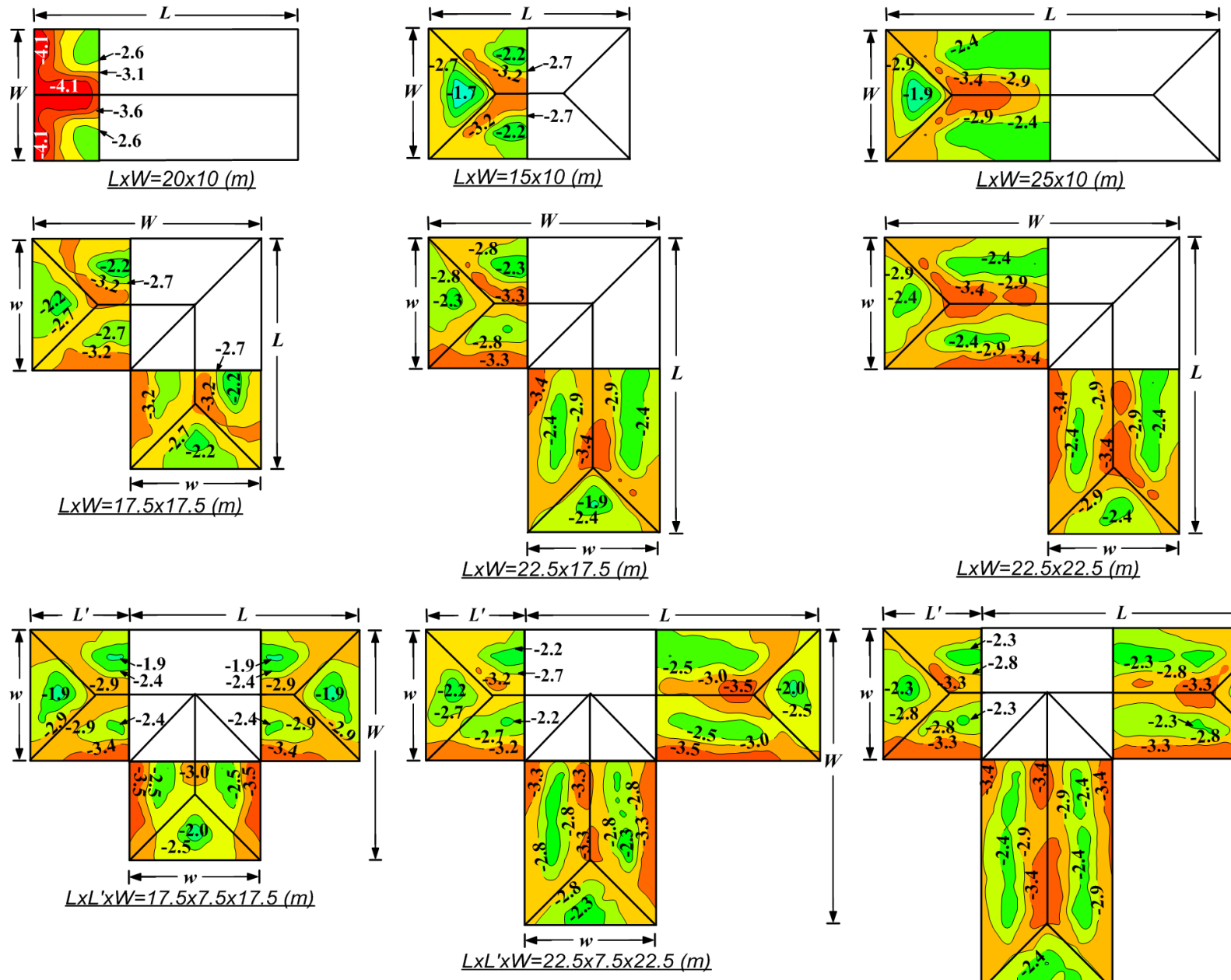

$x^{6} 2^{6} 3^{6} x^{6}$

$\underline{L} \times W=25 \times 10(\mathrm{~m})$
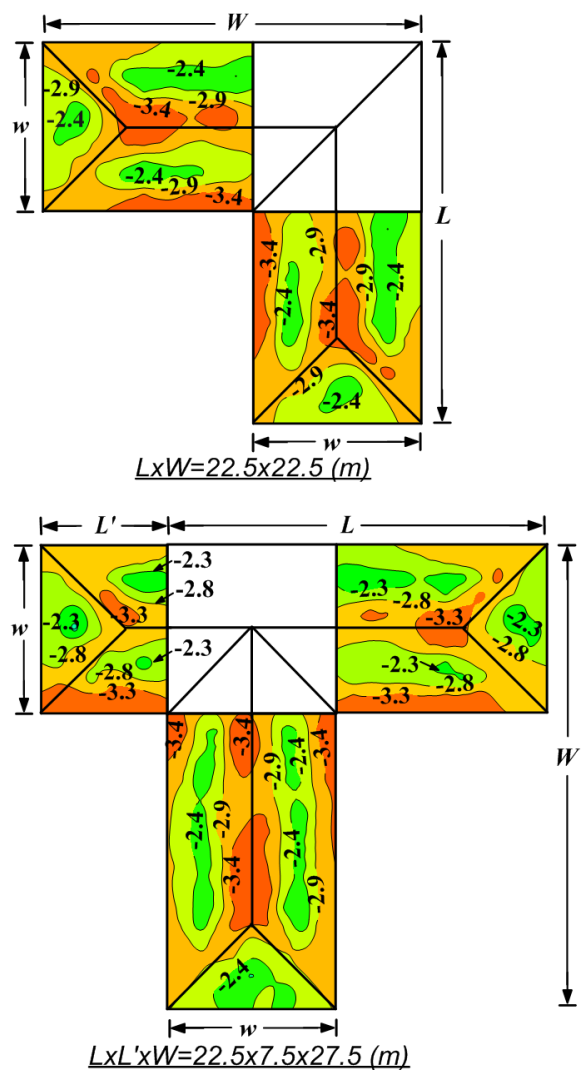

Fig. 13. Most critical wind pressure coefficients from all wind directions 


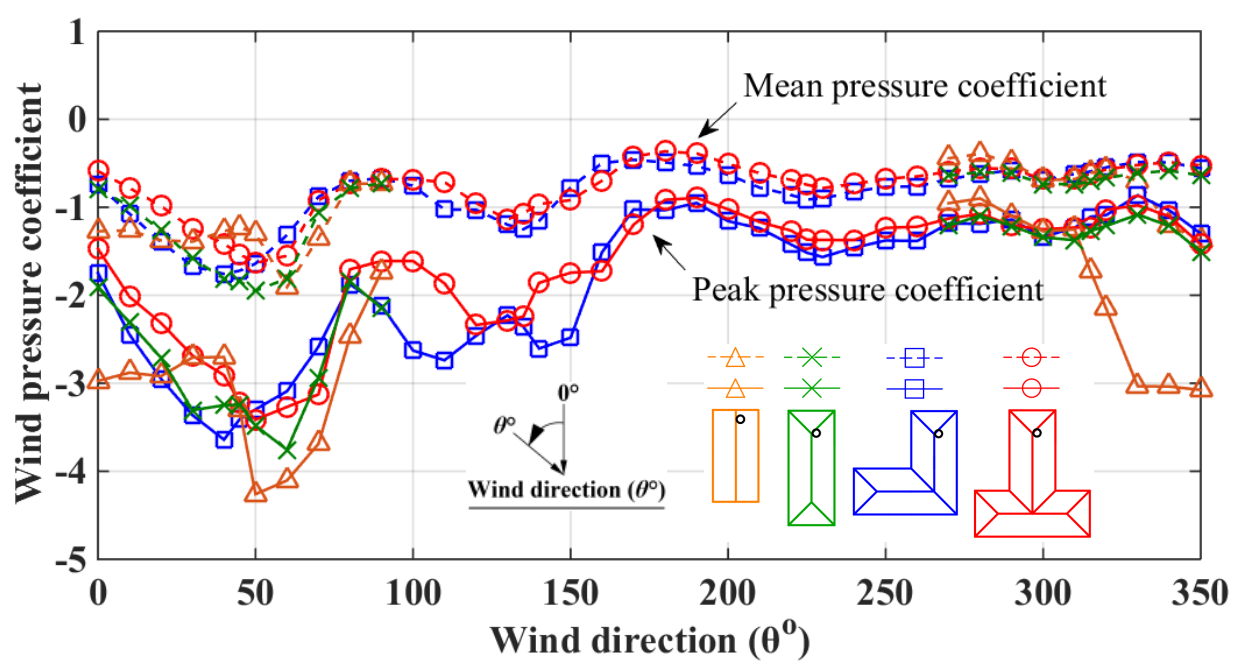

Fig. 14. Wind pressure coefficients around hip and ridge corners for each wind direction 


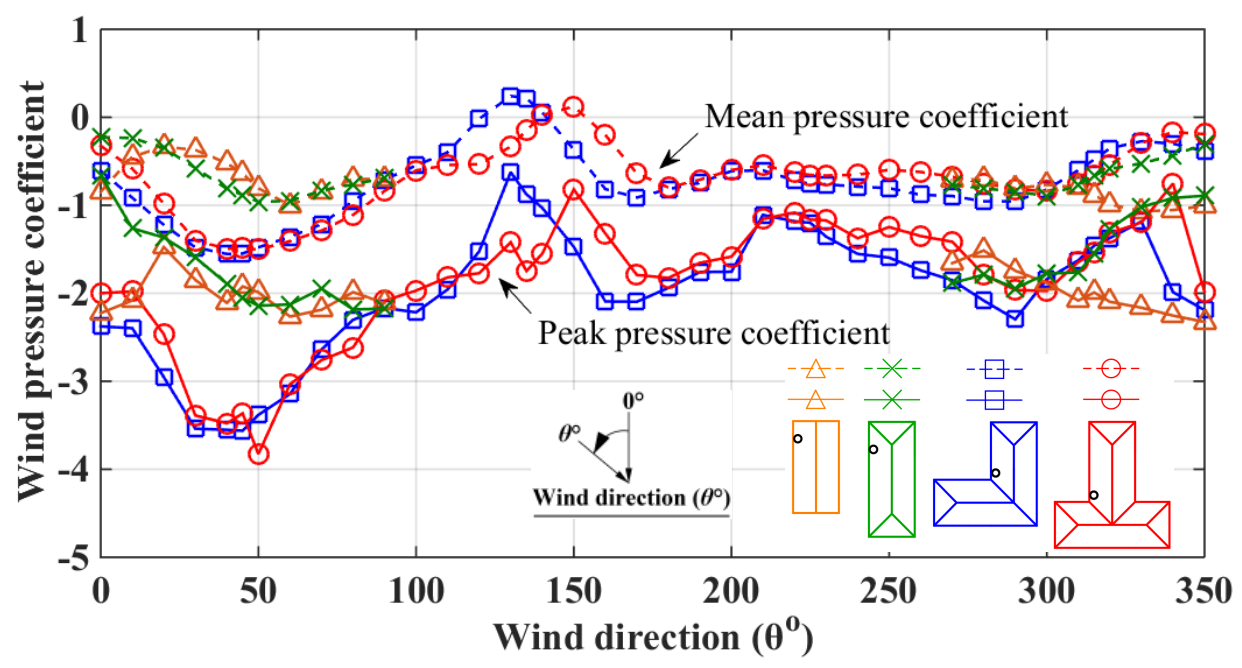

Fig. 15. Wind pressure coefficients around roof eaves for each wind direction 

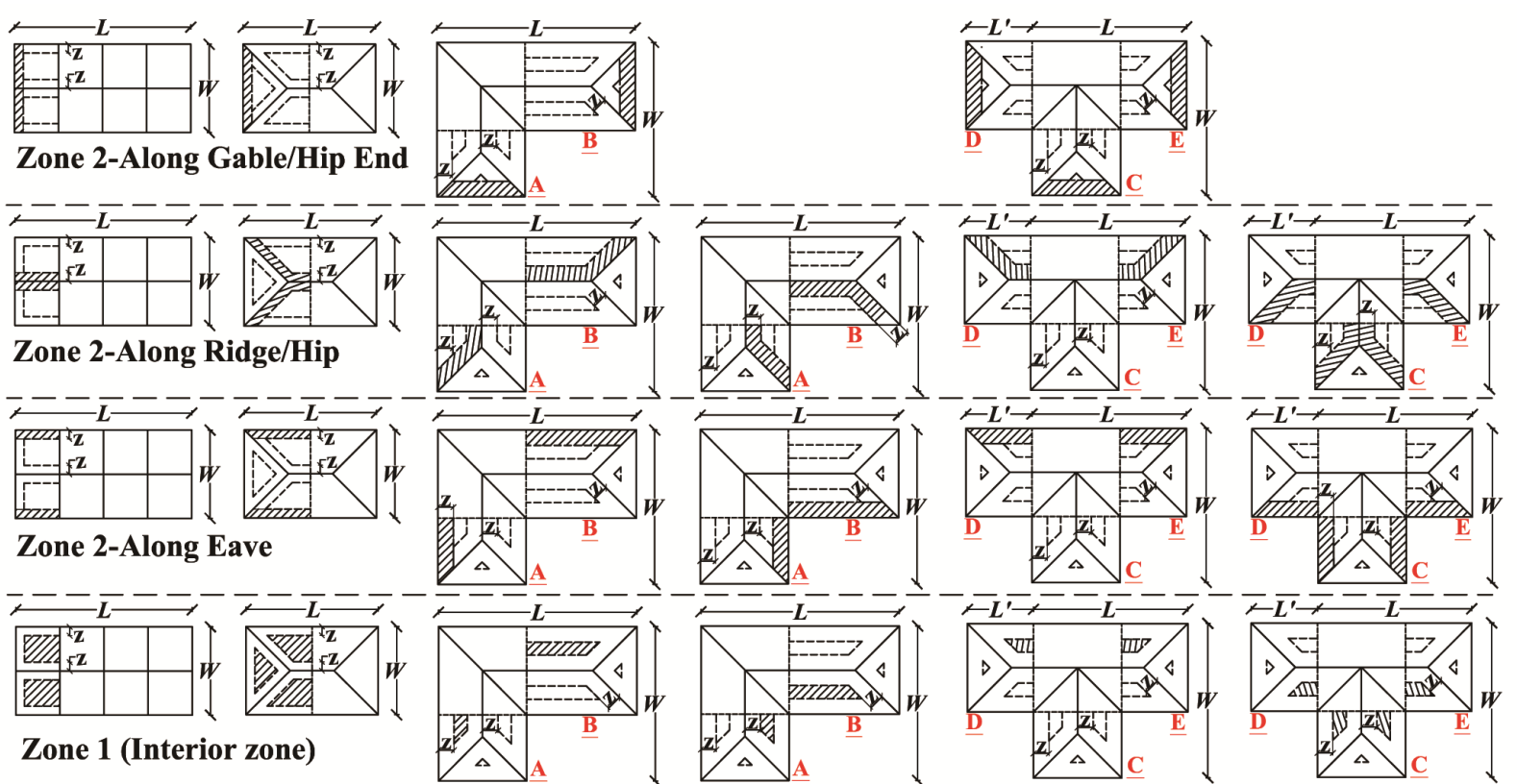

(a)

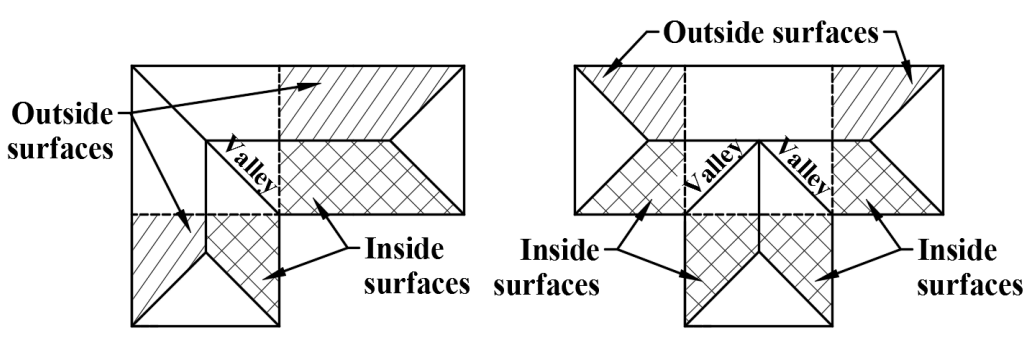

(b)

Fig. 16. (a) Roof pressure zones, (b) Sketch map for detailed roof surface definition 


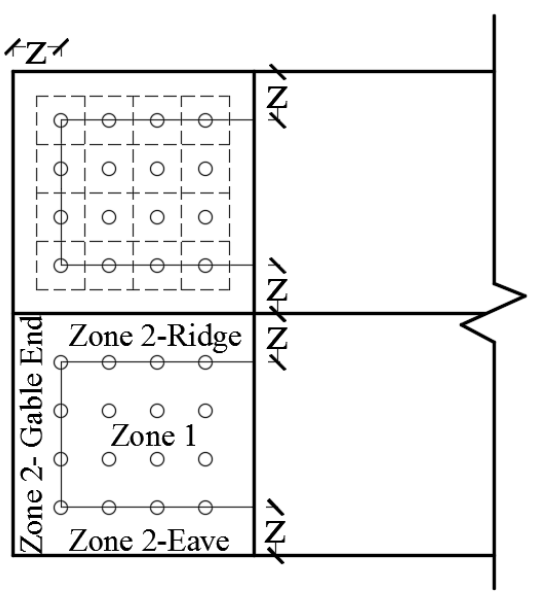

Gable-roofed component

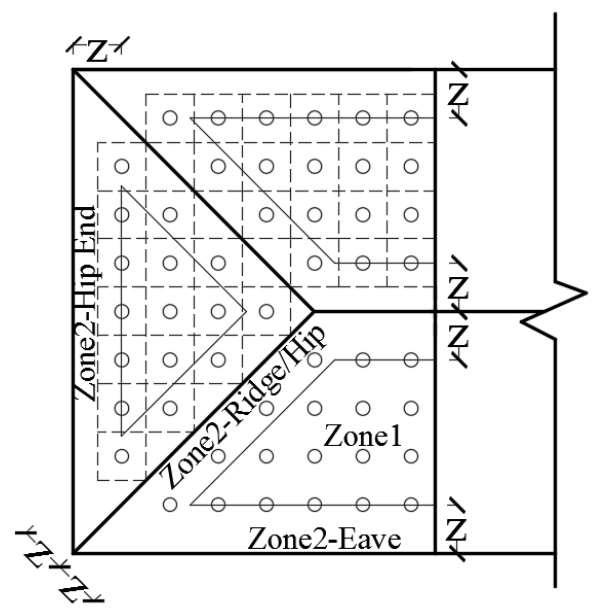

Hip-roofed component

Fig. 17. Pressure tap locations and tributary areas for different roof zones 

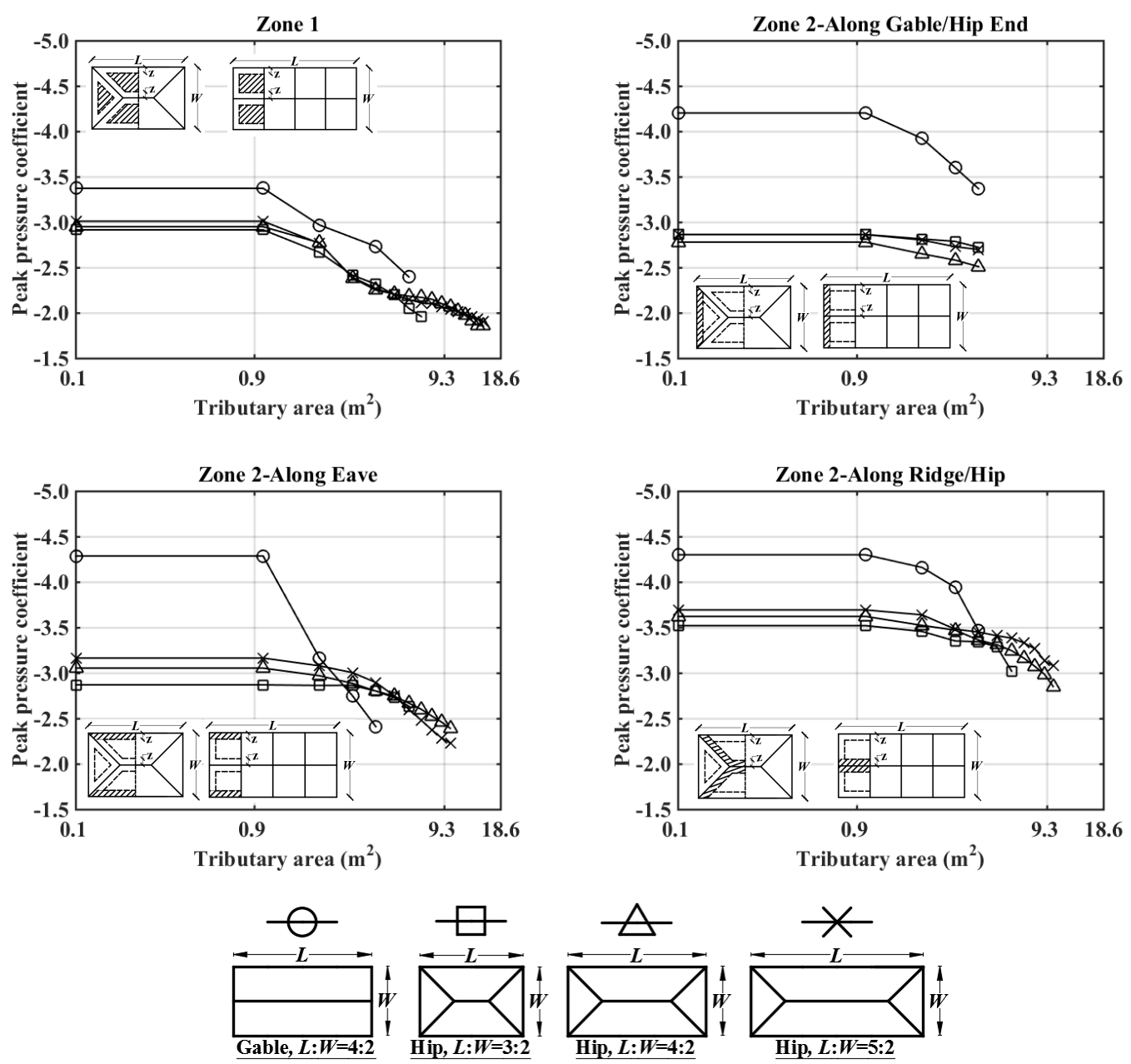

Fig. 18. Variations of peak area-averaged pressure coefficients for all wind directions with tributary areas for different roof zones on rectangular gable- and hip-roofed buildings 

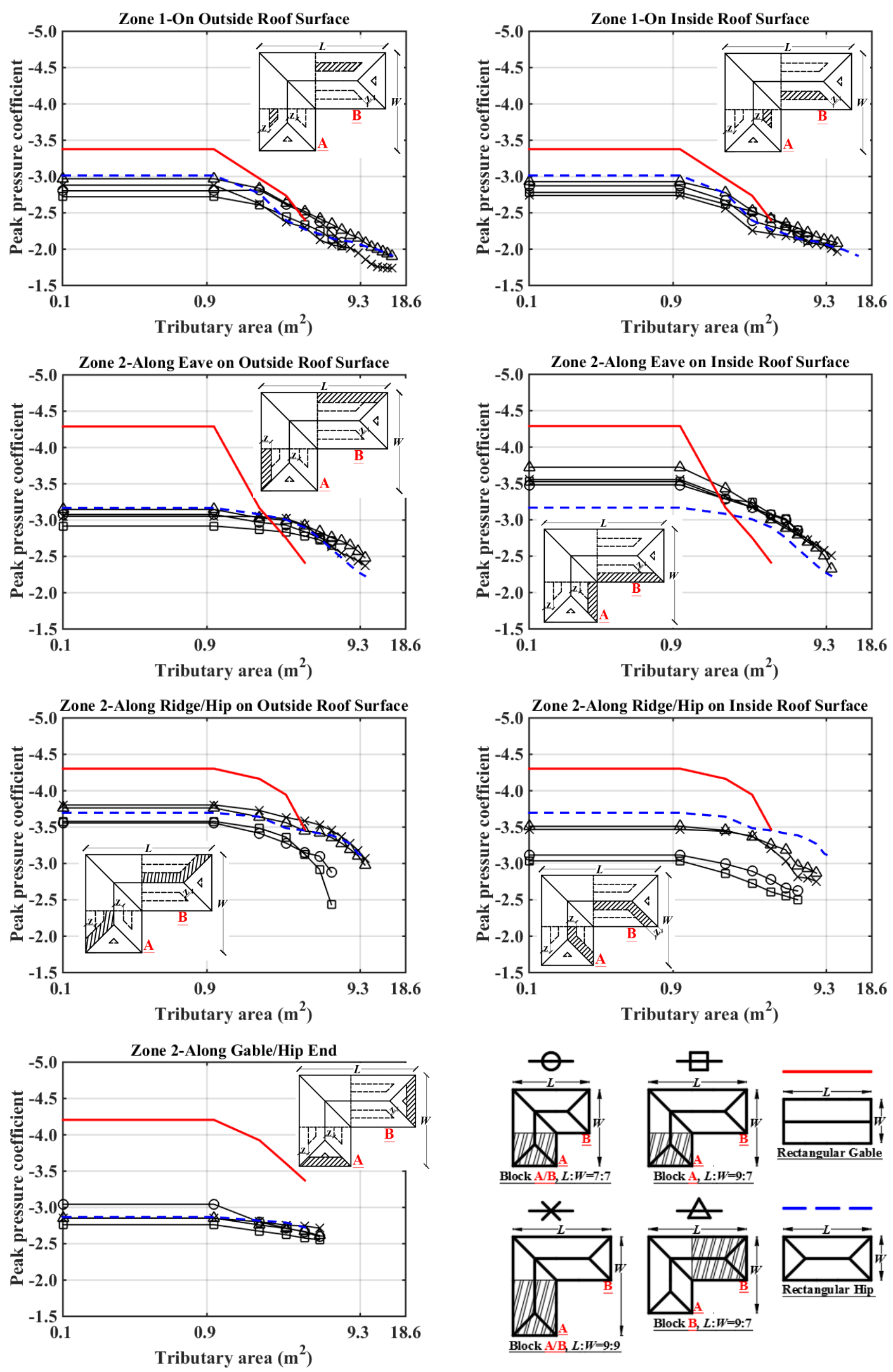

Fig. 19. Variations of peak area-averaged pressure coefficients among all wind directions with tributary areas for different roof zones on L-shaped buildings 

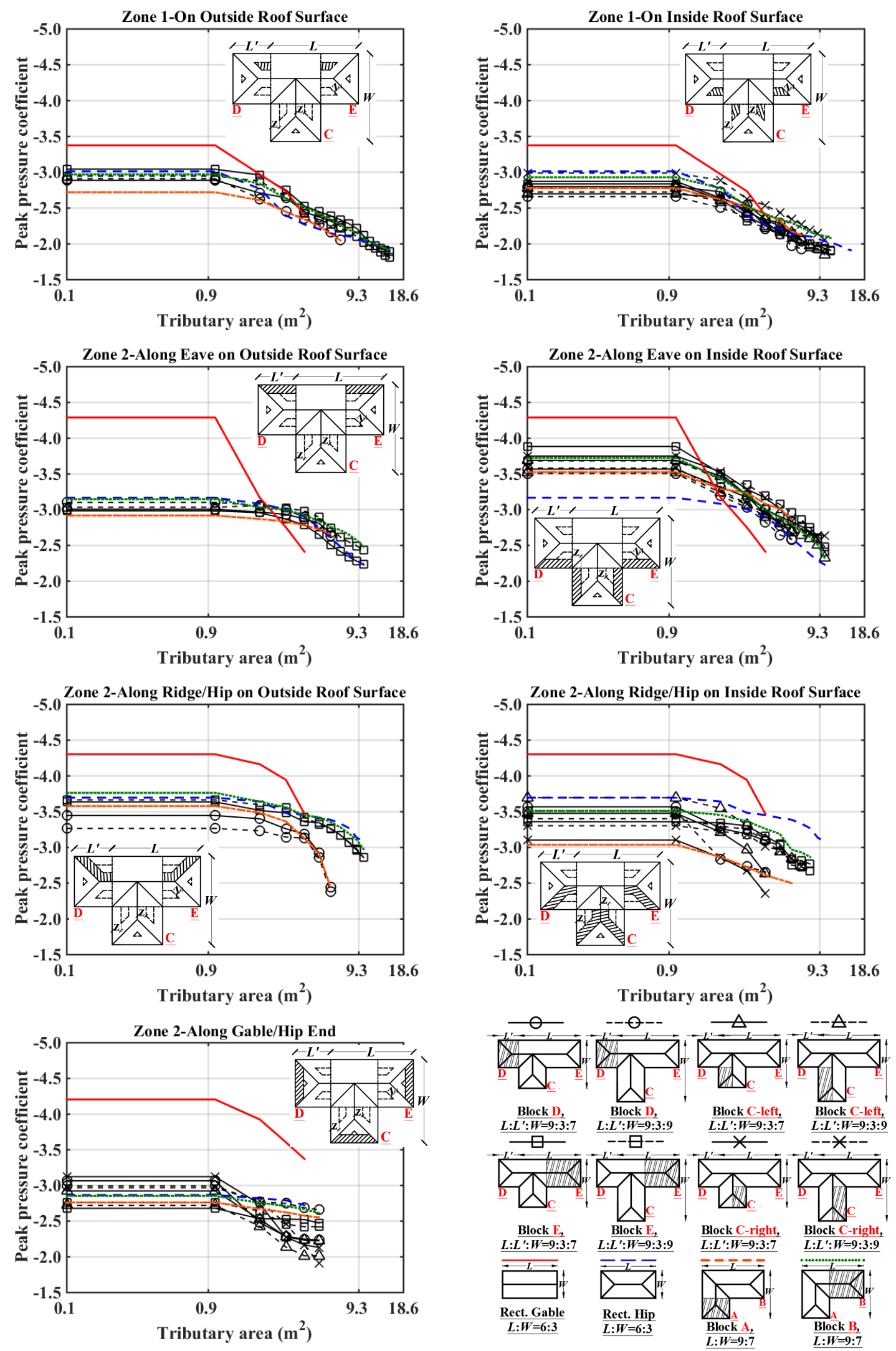

Fig. 20. Variations of peak area-averaged pressure coefficients among all wind directions with tributary areas for different roof zones on T-shaped buildings 


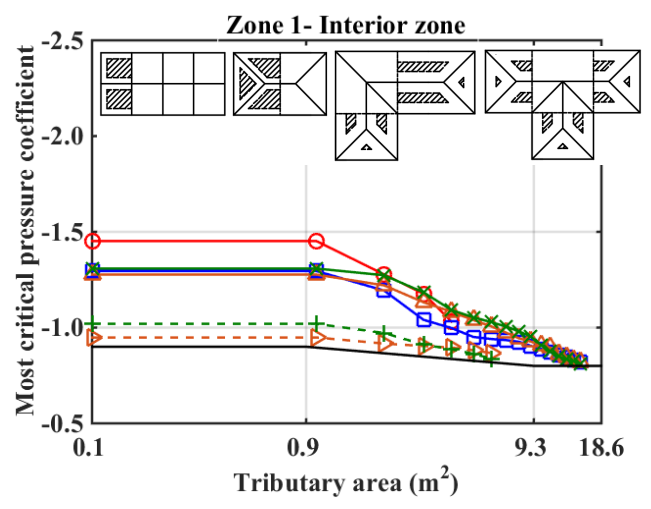

(a)

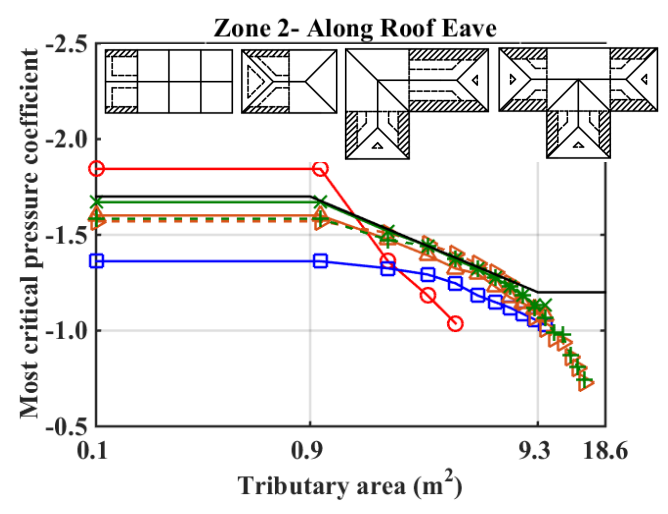

(c)
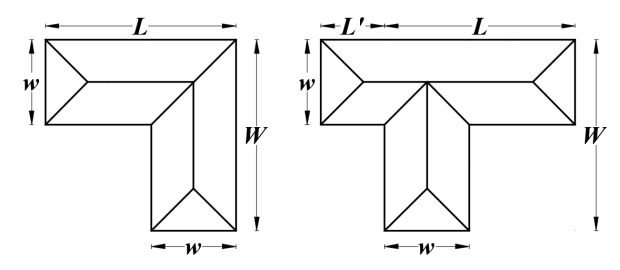

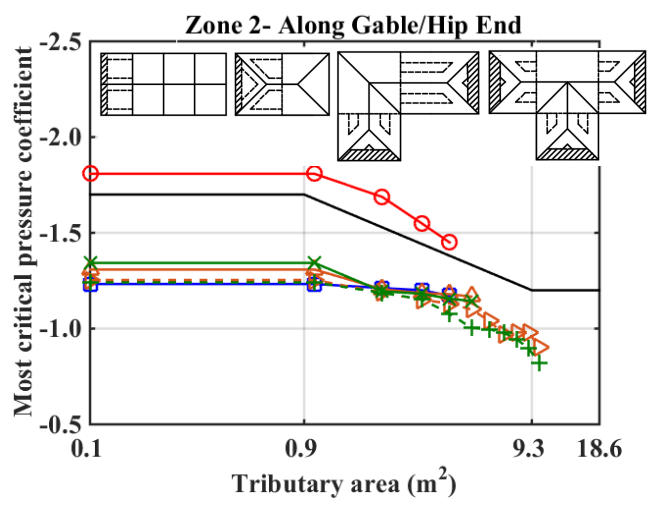

(b)

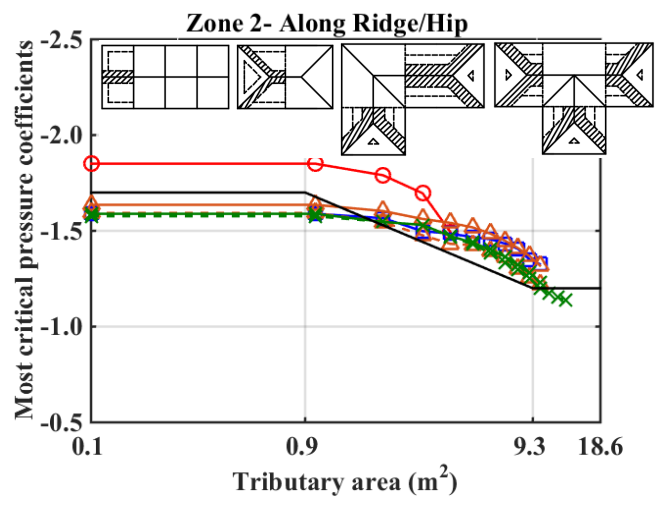

(d)

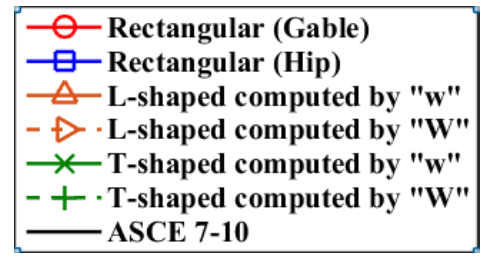

(e)

Fig. 21. Most critical area-averaged pressure coefficients for different roofs zones on rectangular and complex buildings: (a) Zone 1, (b) Zone 2 along gable/hip end, (c) Zone 2 along roof eave, (d) Zone 2 along ridge/hip, (e) Dimension definition and result legend 